\title{
Energy and Food
}

Official Transcript of

Public Briefing and Addendum

May 25, 1978

Washington, D.C.

Published February 1979

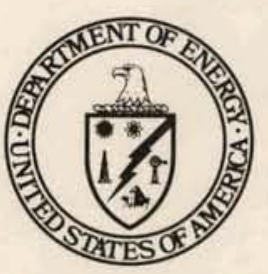

U.S. Department of Energy

Assistant Secretary for Intergovernmental and Institutional Relations

Office of Consumer Affairs

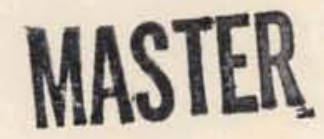




\section{DISCLAIMER}

This report was prepared as an account of work sponsored by an agency of the United States Government. Neither the United States Government nor any agency Thereof, nor any of their employees, makes any warranty, express or implied, or assumes any legal liability or responsibility for the accuracy, completeness, or usefulness of any information, apparatus, product, or process disclosed, or represents that its use would not infringe privately owned rights. Reference herein to any specific commercial product, process, or service by trade name, trademark, manufacturer, or otherwise does not necessarily constitute or imply its endorsement, recommendation, or favoring by the United States Government or any agency thereof. The views and opinions of authors expressed herein do not necessarily state or reflect those of the United States Government or any agency thereof. 


\section{DISCLAIMER}

Portions of this document may be illegible in electronic image products. Images are produced from the best available original document. 
Available from:

National Technical Information Service (NTIS)

U.S. Department of Commerce

5285 Port Royal Road

Springfield, Virginia 22161

Price: Printed copy: $\$ 7.25$

Microfiche: $\$ 3.00$ 
DOE/IR-0041

Dist. Category UC-13

\section{Energy and Food}

\section{Official Transcript of \\ Public Briefing and Addendum \\ May 25, 1978 \\ Washington, D.C.}

Published February 1979

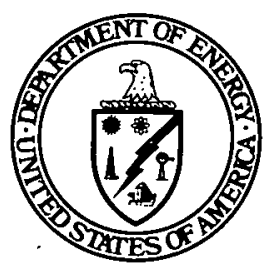

\section{U.S. Department of Energy}

Assistant Secretary for Intergovernmental and Institutional Relations Office of Consumer Affairs

This report was prepared as an account of work sponsored by the United States Govemment. Neither the United States nor the United States Department of Energy, nor any of their employees, nor any of their contractors, subcontractors, or their employees, makes any warranty, express or implied, or assumes any legal liability or responsibility for the accurecy completeness or usefulness of any information apparatus product or process disclosed, or represents that its use would or infringe privately owned rights. 
OPENING REMARKS:

DR. JEAN MAYER, President, Tufts University |

INTRODUCTION:

MR. SAM HUGHES, Assistant Secretary for Intergovernmental and Institutional Relations, DOE

PANEL MEMBERS:

DR. MELVIN H. CHIOGIOJ, Division of Buildings and Community. Systems, DOE

MR. DOUGLAS HARVEY, Director, Division of Industrial Energy Conservation, :DOE

DR. WELDON BARTON, Director, Office of Energy, U.S. Department of Agriculture

MŔ. EARLE E. GAVETT, Office; of Energy, U.S. Department of Agriculture MODERATOR:

MS - TINA HOBSON, Director, Office of Consumer Affairs, DOE 
The following is an index of questions raised relative to the DOE public briefing on Energy and Food. Questions 1 through 38 were submitted by consumer and public interest groups prior to the briefing. Their answers were prepared by DOE program offices. Questions 1, 2, 4, 7, and 9 were addressed also by the panel members.

\section{QUESTION:}

\#1 - On May 20, 1976, the FEA Food Industry Advisory Committee voted on six consumer recommendations for studies of existing information in the following areas: energy.use and nutritional content; energy conservation in food system packaging; energy. waste,through food. waste due to food system inefficiencies; recycling, resource recovery, and waste reduction; food system equipment efficiency labeling; and energy efficiency guide for home food preparation. What happened to those recommendations?

\#2 - On-fairm technologies seem to have received a disproportionate amount of attention in public policy debate. In the future, will other segments of the "food system" (manufacturing and processing, transportation, wholesaling and retailing, out-of-home preparation, and particularly in-home buying, storage, preparation, and waste disposal) be receiving DOE attention more nearly in proportion to their actual energy expenditures and potential energy savings?

\#3 - When will DOE be updating the Food Industry Advisory Committee-initiated FEA report, Energy Use in the Food System? Have any recommendations Tisted in that report been explored?

$\# 4$ - Wi11 DOE invest funds in the development of . K-12 curriculum materials on "Energy and Food" and in preservice and in-service training of teachers on how to teach "Energy and Food" subjects?

\#5. - Are greenhouse operations and urban gardening, if carried out properly, more energy efficient than conventional production, transportation, packing, and marketing systems? If so, what is DOE doing to encourage these practices and to aid in educating the public in correct gardening methods?
PAGE: 
\#6 - Is work being done on the comparative energy

inputs by various gardening techniques: home gardening with and without power tools; organic gardening with and without power tools; small commercial gardening with and without power tools; large commercial gardening with and without power tools?

\#7 - In looking to the full range of solar and renewable energy sources, is DOE prepared to fund and coordinate an effort that would lead to increased energy self-sufficiency for the farm and the farm community?

\#8 - Is DOE planning to assist in the development of do-it-yourself technology for retrofitting solar energy systems to farms?

\#9 - Does the Department of Energy R\&D effort on coal gasification include projects to develop methods for producing the anhydrous ammonia that is so vital to agriculture in the U.S. and developing nations? We also understand that nitrogen fertilizers can be made from alcohol and that leguminous plants and free living nitrogen-fixing bacteria can reduce the need for anhydrous ammonia. What is being done about this?

$\# 10$ - USDA projects indicate that the use of pesticides made from petrochemical feedstocks will increase from 1.4 billion pounds in 1976 to over 2 billion pounds in 1987. Some believe such projections can be cut in half and recommendations to that effect have been submitted to EPA. Does DOE plan to review these recommendations and encourage the acceptance of those that have merit?

\#11 - What is DOE doing to encourage diversification of crops on the farm and to help agribusiness farmers, who are locked into energy intensive monocultures, move to more stable and energy efficient integrated farm operations?

$\# 12$ - Is DOE willing to research and discuss energy requirements for growing various crops for animal feeds, including the use of agricultural and manufactured by-products, and brewery and distillery products? 
\#13 - Rather than subsidizing farmers not to

produce crops, couldn't we encourage these farmers to grow agricultural products heal thy for the land and useful as a net energy source (biomass)? What is the annual cost of such current subsidies?

\#14 - What research is DOE doing now to compare 105

the energy requirements of various food processing and preserving techniques: canning by home, community, and by industry; frozen goods; dried products; and fresh produce?

\#15 - Has DOE initiated any studies comparing the. nutritional content of food to the energy required by the various industrial processing techniques currently used by large manufacturers? What part of the energy used by manufacturers is used to process raw agricultural products (and chemicals) into "junk food" with little or no nutritional value?

\#16 - Has DOE published a comprehensive and understandable economic and energy comparison of the use of returnable bottles, cans, and nonreturnable bottles? What were the results?

\#17 - What kind of studies have been made to define food system packaging and overpackaging? Have any studies been initiated to define the comparative energy requirements of container styles and designs used in the food system? What efforts have been made to encourage industry to use less energy intensive packaging materials?

\#18 - Should there not be a policy of consumer education on the comparative energy requirements of certain food containers, with advantages and disadvantages explained for various types?

\#1.9 - An FTC ruling prohibits empty trucks from picking up goods from a supplier's warehouse enroute. Instead, other carriers haul these goods over the same routes followed by the empty trucks. A Federal Energy Administration estimate placed the potential fuel savings by eliminating deadheading at 100 million gallons of gasoline per year in the food industry alone. Is any action being taken to eliminate this situation? 
\#20 - In the Eastern U.S., trucks have captured essentially all of the long haul refrigerated food business from the railroads. As a result, there were less refrigerator cars in service in the U.S. in 1976 than in 1975. What is being done to encourage use of the more energy efficient rail transportation in the hauling of perishable foods?

\#21 - What is DOE doing and what recommendations are being made in terms of our food transportation system? More specifically, why does the U.S. encourage long distance shipment of food and worldwide "global supermarket" at the expense of local food self-sufficiency?

\#22 - Wi11 DOE address backhaul and intercorporate hauling issues, focusing on energy waste and the added costs to consumers?

\#23 - What is DOE doing to evaluate al ternative food distribution systems, such as farmer's markets and food consumer cooperatives, and to encourage those that are sound from an energy and economic point of view?

\#24 - Is consideration being given to the fact that hundreds of thousands of meals are being delivered daily by retired volunteers to home-bound elderly and handicapped persons? What can DOE do to help ensure the continued availability of this vital service in the face of rising gasoline prices?

\#25 - Could DOE provide the public with a chart that would explain the energy, economic, and environmental costs of various types of foods in terms of nutritional values?

\#26 - What is the Department of Energy doing to encourage a shift in eating habits toward consumption of highly nutritions but less energy intensive foods?

\#27 - Could DOE and USDA cooperate in comparing the energy, nutritional and economic factors of various forms of shopping, refrigeration, packaging and preparation of food? 
\#28 - What do we know about the varying efficiencies

of gas, electronic, and microwave energy sources?

of stove top versus oven cooking methods? How has

this heen studied and what problems has it encountered?

Can we rank varying factors which affect cooking efficiencies?-

\#29 - Is any effort being made by DOE to encourage

restaurants, cafeterias, and coffee shops to decrease

food waste through such means as serving portions

more suitable to the consumer?

\#30 - The Department of Agriculture has a cosmetic grading system for fresh fruits and vegetables and other products which results in significant food and energy waste. Has DOE encouraged USDA to evaluate and change this system in light of today's energy priorities?

\#31 - What is DOE doing to encourage EPA to rely more heavily on pretreatment of waste at the source before they are released into a public system? What is DOE doing to encourage EPA to further emphasize land disposal of composted waste as the preferred method of dealing with municipal waste?

\#32 - What is DOE doing to evaluate the potential energy savings and to encourage practices that will prevent or recover nutrients that end up in the sewers and become contaminated by other wastes?

\#33 - As the water table drops, more and more energy is required to pump water needed to support agriculture. What is DOE doing, in cooperation with other departments and agencies, to encourage water conservation in those sections of the country impacted by this situation?

\#34 - Given the developing energy and food shortages throughout the world, should the U.S. become increasingly dependent on imported food from developing countries? What role does DOE play in the transfer of agricultural technology to developing countries to ensure that the technology is appropriate in terms of projected energy availability? 
\#35 - The great need of consumers is political

direction from the executive department

spokesmen to tell us, to suggest, to encourage us to adopt and indeed find new ways to conserve energy in the production, processing, and use of food--an area of energy within the control of every individual and business to some $\bar{e} \bar{x}=$ tent. Can DOE help us here?

\#36 - The new technologies being funded by DOE will reduce energy costs and the costs of food, and thus, will determine the U.S. diet of the future. Wi 17 DOE consider the nutritional value of the food when promoting its more efficient production?

\#37 - Even though the weatherization program exist for low-income; it is simply not enough.

If in D.C. alone only 40 homes have been weatherized, how long will this process take, and is there enough funding available for this? How, until then, will people be able to afford food?

\#38 - Please answer question \#10, particularly

with reference to DOE's and USDA's input in investigating alternatives to petroleum based pesticides. What is the percentage of nonchemical pesticide control methods at USDA and DOE?

Questions from the floor at the public briefing on Energy and Food:

\#39 - It appears that many of the issues

which have been discussed today could be clarified or delineated through the use of surveys to find out how the general public feels, their attitudes toward energy conservation, as well as targeting some of the subject areas in the energy picture, where the public needs more information and education. Is any such program of research anticipated by DOE? 
\#40 - Could you compare the cost of alcohol

fuel to biomass sources and to a variable-

source material?. Will you use the grain proper

or will you use the crop residues? When

Secretary Schlesinger comments that the cost

ot ethanol tuel will be $\$ y 0$ a barrel as opposed

to a $\$ 30$ a barrel for methanol from coal, which

biomass is he assuming; the finished grain or

the crop residue?

\#41 - If we don't have enough energy, is the

Department prepared to establish priorities of

energy usage? Has DOE begun to identify those

activities which consume significant amounts

of energy and which, like the production and consumption of cigarettes and feedlot beef, result in major national heal th problems?

And, if so, what plans have been made to inform and consult with the public during this process of identification?

\#42 - I am with the Grocery Manufacturers of

America and we have had various calls at the last minute inquiring what publicity had been given to the holding of this meeting. Had the notice of it been published in the Federal Register?

\#43 - Is there work being done on comparative

energy inputs for various home gardening techniques? We would like to see the Government begin to encourage people once again to go back, as an entire country, into private gardening. Could we have some comparative energy values on that some time?

\#44 - What is DOE doing to protect consumers from higher food prices caused by the President's higher energy prices? What study has the Department conducted or will it conduct with regard to the impact of higher energy prices on food?

\#45 - What is your advice to schools with regard to serving fast-food lunches to children, in terms of their costs and in terms of nutrition?

\#46 - Have you found that the food industry or the food system has made a definite effort to conserve energy? What types of projects is the food industry working on in conjunction with DOE to develop both new technologies and new processes that do conserve energies? 
\#47, - I want to ask if any work is being done

to improve energy use in the two different approaches to pest control; integrated pest management and chemical pest management?

\#48 - What is being done to reduce the wastefur use of energy associated with open refrigerator display cases, runaway increases in brand selection, excessive lighting, and proliferation of so-called convenience foods in supermarkets?

\#49 - I would like to know what suggestions can be offered to higher education institutions as to the thrust that they should adopt in training individuals to be food and energy practitioners and also to be general consumers?

\#50 - I am concerned with the percentage of research done at USDA and DOE, if any, on nonchemical means of pest control.

\#51 - Increased energy costs must be absorbed by reduction in expenditures in other areas, frequently in the food area which has already risen in cost due in part to the increased energy costs. What is DOE doing to help offset this impact, particularly on persons already in the grip of poverty? What resources and documentation on the extent and amelioration of this problem are available?

\#52 - The present USDA beef grading provides incentives to use more energy-intense methods at increased costs to farmers and to the nutritional detriment of the consumer. Will USDA respond favorably to legislative initiatives to reverse this built-in energy inefficiency, or is it planning to introduce its own standards in this regard? 


\section{$\underline{\mathrm{P}} \underline{\mathrm{R}} \underline{\mathrm{O}} \underline{\mathrm{C}} \underline{\mathrm{E}} \underline{\mathrm{E}} \underline{\mathrm{D}} \underline{\mathrm{I}} \underline{\mathrm{N}} \underline{\mathrm{G}} \underline{\mathrm{S}}$}

MR. HUGHES: Good morning, and welcome to the 6 th in our serles of consumer information briefligs:

I am Sam Hughes, an Assistant Secretary of the Department of Energy interested in the outreach activities of the Department and particularly in this series of briefings.

This one is on "Energy and Food" and it is the last in our series for this fiscal year.

The purpose of the briefings, as I think probably many of you are aware, is to respond to questions which consumer and public interest groups and other members of the public have about energy issues which most concern them.

I might say that, with respect to energy and food relationships, this is an area where the Department of Energy, at least in a structural sense, has not given great emphasis to the subject matter and we, therefore, welcome our friends from the Department of Agriculture who are on our panel today and can assist us.

We do look forward to your questions and comments as a source of guidance to us with respect to the directions in which we can move forward in this general subject area of energy-food relationships.

This entire briefing, like previous ones, is being videotaped for distribution to our Regional offices In, order to give the presentation of views expressed a wider range.

Our discussion today focuses on energy and food and some of the issues concerning the relationship between the cost of energy and 
the cost of food, plus a wide variety of measures to reduce energy consumption throughout the food system.

My first task, other than to make these brief introductory comments to you, is to introduce our keynote speaker. It is a real pleasure. He is Dr. Jean Mayer, the President of Tufts University, and, as I think all of you know, a leading expert on nutrition.

A good many Washingtonians know of him through his colum in. the Washington Post, in which he answers questions from consumers on nutrition.

I think I first met Dr. Mayer a few years ago, perhaps nine or 10, In the White House in connection with a conference on nutrition, then in its early stages in the Nixon Administration. So, he has some familiarity with our city and our Government as well as with the subject of nutrition, and it is a real pleasure to welcome him this morning to set the tone for our discussions and your questions and answers.

Dr. Mayer?

DR. MAYER: Thank you, Mr. Hughes.

There are a number of good reasons why we should be preoccupied with the relationship of energy to food supply and to nutrition.

On a worldwlde basis, it seems quite obvious that the way in which we are going to feed the additional two billion or so people, who are going to come and inhabit the earth between now and the year 2000, is going to be very heavily predicated on the techniques of the so- 
called green revolution, which basically involves an agriculture heavy in petrochemicals.

It is probably only within the range of 15 to 20 years that less energy-intensive methods will be available, but until then the needs of agriculture for energy in the world at large are going to be heavy, which is one more reason why all of us in richer countries should be very careful with our use of energy.

In the United States, we have a somewhat different situation. In the past 20 years or so, the nature of our food supply has changed very rapidly--to an extent which most of us on a day-by-day basis hardly perceive, precisely because it is so gradual.

At this point, the best estimate we have is that only 18 percent of the total energy used in our food system is involved in agriculture as such. There are much larger components; processing of food--probably something on the order of 33 percent; use of energy in the home--on the order of about 30 percent; and transportation--about 9. percent; leaving something on the order of 8 to 10 percent for wholesale and retall activities.

Thus, agriculture, which is obviously at the base of our whole food system, represents a relatively small component of the total cost, even though as one looks into the amount of research that has gone into energy saving, it has occupled 'a pre-eminent place relative to the rest of the 80-plus percent of the energy used in other ways. 
The. use of energy in the food system in the. United States has Increased very rapidly.

For instance, between 1960 and 1970, the energy used in the food system has grown at the rate of 3.3 percent per year, which is more than double the rate of population growth. The reason this has happened is because, as I mentioned before, the type of food supply we have has changed very rapidly; away from basically unprocessed or very lightly processed foods, harvested in many cases locally, to the greater and greater use of very highly processed foods, in entire processed meals, based on the combination of various components from foods with the addition of appropriate additives and with a very large component of packaging, freezing, canning, and so on, depending on the type of food we are talking about.

Here are some figures which may be useful; in a large supermarket, there is something on the order of 16,000.1tems. The food industry introduces roughly 500 new 1 tems every month, of which only about 500 survive, but there is still a constant change and increase in the number of items, and constant replacement going on.

This type of change, I think, is not going to decline. The economic research service of the USDA sees the use of frozen foods such as TV dinners, pizzas and snacks, which are falrly high in terms of energy costs, doubling in terms of consumption between 1974 and 1980 . In other words, in the six years of that period, the total energy use for such foods will have doubled. The consumption of diet 
drinks and ready-to-eat cereals, which also tend to be high in terms of energy costs, is also increasing at a rapid rate.

All this makes it very unlikely that, unless checks are applied, the use of energy for the food system is going to decrease. The interesting thing is that some of those changes in food habits have been useful in terms of nutrition, which is, after all, the reason for food production and food consumption.

But by and large, this is not what has happened. Certainly I don't want in any way to minimize the fact that canning and the avallability of frozen foods, particularly frozen fruits and vegetables, has made available a much greater variety of fruits and vegetables during certain times of the year in regions like New England than were hitherto available, and to that extent, this has presented a considerable increase in the quality of our food supply.

I don't want to minimize the fact that some ready-to-eat foods have permitted a considerable decrease in the amount of time spent in the preparation of meals and has been a major factor in the so-called Women's Liberation.

On the other hand, there is very little doubt that, taken as a whole, the new foods tend to be very high in sugar, high in saturated fat, and high in salt; precisely those elements of the diet which give nutritionists the most concern. Salt, because of the demonstrated correlation between a high salt content in the diet and hypertension. Saturated fat, because of the relationship to cholesterol, and sugar, 
because of the lack of nutrients accompanying sugar, and at the very least, its bad effect on teeth.

Now, I would also like to point out that almost anything we say is really to be looked at in some detall. I have mentioned the fact that, by and large, the shift in our food supply and the shift from home-cooked and home-prepared foods to mass-prepared foods is accompanied by a considerable increase in energy costs.

This is not always necessarily the case. Take bread, as an example. The average bakery takes less energy in preparing, baking and wrapping a loaf of bread than the home cook does even if he or she cooks six loaves at one time in an oven.

Baking a couple of loaves of bread in one's oven, pleasant though it may be as an occupation, and delectable as the result may be, is horrifying in terms of cost, compared to what an industrial bakery will do.

By contrast, a point that I think is worth making is that sugar, and the increase in use of sugar, is extremely expensive in terms of energy. Some people think of sugar as a cheap source of calories. It is cheap in terms of cents per calorie, probably because it provides nothing but calories.

The agricultural cost of growing sugar is not very high when we see figures of 96.5 kilocalories per pound for beet sugar and 61.8 kilocalories per pound for cane sugar. That looks very low when you compare it to 430 kilocalories per pound for corn, 154 for potatoes, and 
750 for wheat, and I think people have been bemused by those production figures.

On the other hand, if you look at the processing figures, you find that processing beet sugar takes 387 kilocalories per pound and, with a conversion rate of 8.19 pounds of beet per pound of sugar, this gives roughly a figure of 4200 kilocalories per pound of refined sugar. This compares with 1960 kilocalories per pound for unrefined white bread flour, or 1740 for whole-wheat flour.

So, again, unless you look at the whole process and the production from inception, from the manufacture of the tools and the putting up of the plant, to consumption, you can end up with extraordinarily wrong figures.

The much lower calorie costs of flour, whether white enriched flour or whole wheat flour, as compared to sugar, is accompanied by the fact that flour brings a great many nutrients to the diet while sugar brings none.

Indeed, when you look at the total distribution of energy costs in the food industry in the United States, you find that wet corn milling, malt beverages, and the sugar beet industry, all of which produce what may be called, roughly, empty calories, are among the six food industries using the most energy in the United States.

So, the type of food industry that is not in the traditional American pattern, but which has been allowed to develop in the last 15 years is one which has profoundly changed not only the type of diet, but 
the type of energy cost in the United States. We all recognize that people are free to choose their diet, but we must also remember that we have been bombarded by between three and four billion dollars worth of advertising telling us what to eat every day. But if one made those adjustments to bring the diet in 1978 to roughly what the diet was in 1960, one can estimate that the agricultural costs, the energy costs. of agriculture and processing would be decreased by something between one-half and one-third, which is about 3 percent of the total energy use In the United States.

Now, in àn emergency situation, in a very tight situation, the consumer who voluntarily makes this type of energy savings through diet modifications, and uses home appliances better, could represent a very substantial saving in the energy costs in the United States.

Education in using appliances better is obviously extremely important. I know that there is considerable concern right now about improving appliances, including improving stoves and ovens.

The use of pilot lights, in some cases, several pilot lights, ends up as one-half of the gas delivered. Perhaps as much as one-tenth of all the gas used in the United States is used for pilot lights.

On the other hand, we have to recognize that the life expectancy of a stove is very long, and replacing all the stoves in the United States is going to take something on the order of 20 to 30 years. By the same token, it has been found that different housewives use their stoves for the same type of recipes in such a way that some use 50 
percent more gas than others. Again, there is a possibility of enormous savings.

The point I want to make is simply that we have a type of food system which has become more and more expensive in terms of energy costs, not so much at the agricultural end as at the processing end, and in the home.

Not all modifications in the food system have involved more energy use, but a great many of them have. And furthermore, many of the changes which have become more expensive in terms' of energy have accomplished very 1ittle. In fact, they have been counterproductive in terms of the nutritional quality of the diet.

What I am suggesting is that, first of all, we ought to try to get very much more detailed data on the real energy costs of processes-which involves not just the Industrial process itself, but involves everything from manufacture of implements to dishwashing, recognizing that we have found a number of situations where the manufacture of the machinery may use as much energy as the running of the machinery, so, secondary inputs prove extremely important. We also need more education of the public both in terms of food choices and in terms of methods of food preparation.

Thank you very much.

MR. HUGHES: Thank you very much, Dr. Mayer, for giving us some fundamental facts with respect to energy and food relationships and particularly, in my judgment, for your emphasis on what might be termed 
the life cycle energy costs of food preparation processing and consumption in the home.

I would like now to introduce our panel. Dr. Weldon Barton is the Directur of the office of Energy in the U.S. Department of Agriculture. He reports directly to the Secretary and is responsible for first coordinating and reviewing energy programs and policies throughout that Department for providing leadership within the Department on new initiatives in the energy area and for representing the Department on energy matters with Congress, the public and other administrative agencies.

The next panel member is Dr. Melvin Chiogioji, who is the Assistant Director for Systems Analysis and Technology Transfer of the Division of Buildings and Community Systems in the Office of Conservation and Solar Applications of the Department of Energy. His office is responsible for energy conservation in bulldings and community systems, which includes putting together informational materials on energy and food for the consumer, developing curricula on energy and food, and managing the Department of Energy's appliance labeling program.

Earle E. Gavett is another Department of Agriculture member whom we are fortunate to have with us. He is the Staff Economist in the Office of Energy of that Department. He has been involved in developing energy conservation programs in agriculture for the past five or six years.

And our fourth panel member is Douglas G. Harvey, Director of Division of Industrial Energy Conservation of the Office of Conservation and Solar Applications in the Department of Energy. 
His office is responsible for developing energy conservation programs in the agricultural and food production sectors of our economy. The program, as the name 1mplies, emphasizes reducing energy consumption by licreasing efficiency.

Now, I would like to turn the meeting over to our moderator, Tina Hobson, whom many of you have been introduced to before, but those of you who have not had that opportunity, Tina is the D1rector of the Office of Consumer Affairs in the Department of Energy and is responsible for helping to facilitate communications between the Department and energy consumers helping all of us to better understand the needs and concerns and viewpoints which you have concerning energy policies and programs and to undertake activities like this one which bring us together in dialogue.

Tina?

MS. HOBSON: I think I will fust stay here at the table because we want to move on pretty rapidly.

Thank you, Sam.

Before the panel begins, and before I ask the panel to comment on what Dr. Mayer said, I want to go over quickly the ground rules, as we usually do.

Four of the 34 questions submitted by consumer and public interest groups in advance of the meeting will be addressed by the panel during the next approximately 20 minutes. We have selected these questions because they appear generic to all the answers. However, I 
want you to know that the remaining 30 questions listed in your program w111 be answered in the transcript.

The questions appear as they were submitted to us. They were not altered or rewritten.

In some cases, more than one group asked the same type of question. The list of who asked what is avallable in my office. I also want you to know that Fern Spivey is our officlal timer. Fern, would you please stand? Panel members will be given a one minute warning when they have one minute remaining of their allotted time.

When five minutes have been used, I will ring this bell. I have a feeling that there are a lot of people with a lot of information up here on the stage and we want to make sure that everyone has an equal chance to express their concerns.

Now, I would like to go on and first ask the panel if anyone would like to comment at this time on what Jean Mayer said because, after you speak, we are going to give him a chance to comment on what you said.

\section{Weldon?}

DR. BARTON: I will comment very briefly on Dr. Mayer's discussion.

He presented a good general overview of energy problems as they relate to the food system.

Some of the things he discussed are beneficial on a broad range of bases. Energy is an important component, for example, of the 
fruits and vegetables production in New England, which Dr. Mayer mentioned. Other important considerations of local fruit and vegetable production are better quality and, perhaps, lower food prices. Those are some other factors that, alung with energy savings, perhaps make these practices highly beneficial in total even if you could not perhaps justify them strictly in energy terms.

It seems to me that $\mathrm{Dr}$. Mayer's comment that you have to look at the food system as a whole if you are going to realistically assess energy costs is right on point.

He used the example of sugar with low energy costs for production, but with high energy requirements for processing. A large number of examples could be given in which you might have savings at the production stage, but which might cancel out at the transportation, processing, or retalling stage. If you are going to be realistic, you have to get an overall picture of: the energy impact from production through retalling, as Dr. Mayer has indicated.

MS. HOBSON: All right, thank you.

Why don't we take you next, Mel? I think you are going to answer question four. Question four is; Will DOE 1nvest funds in the development of K-12 curriculum matertals on "Energy and Food," and in pre-service and in-service training of teachers on how to teach "Energy and Food" subjects?

DR. CHIOGIOJI: Thank you, Tina.

DOE has been doing some work in the area and we feel that this particular area is important. For example, the Education Program Division within the Department has been developing energy curriculum 
materials which are appropriate for a variety of age levels in both the primary and secondary schools.

Some of these educational materials relate to food and energy and they are avallable if you desire to have any of this by contacting the Education Program Division.

One example of a publication that is available would be suitable for a standard course of study at the senfor high school level, that is the 10th to the 12th grade levels, is entitled "Agriculture, Energy, and Society."

This particular course of study is an interdisciplinary unt which would help students to examine the nature of present-day agricultural methods and examine the impact of these particular methods on energy resources.

Another publication which is avallable is "Community Workers and the Energy They Use." 'What this particular publication does is to report on the energy consumed by all types of workers, Including farmers and grocers. This particular course is sultable more for the primary levels than for the secondary levels.

The Division of Educational Programs has also planned and organized various other methods for disseminating materials and we try to work such that we can incorporate these types of materials or educators can Incorporate these types of materials as part. of their teaching curriculum. 
The division also sponsors a Federal development program which provides in-service type training to teachers to try to prepare them to Instruct students on varlous aspects of energy and this effort includes things 1ike workshns and the same sort of things for universities.

We are also trying to educate educators.

For example, Cornell University was funded, under our program, to develop a project entitled "Energy Use and Conservation in Food and Nutrition Systems." In addition, the University of Iowa is being supported in a home economics energy education project.

Other agencles, other than DOE, are also working in this particular area--particularly HEW. They are dolng programs that cover every level and aspect of education.

I belleve that educational proposals including energy could be funded in such HEW programs as community education, educational innovation and support and environmental education, the Teacher Corps, and programs of this sort.

There have been about 25 energy and food-related programs which HEW has funded in the last five years.

A variety of other programs have been developed to educate residential consumers, with application within and outside the educational system. These consumer education programs devote much attention to home food preparation and storage.

For example, one publication that we have is called "Energy Conservation in the Home." This is a guide for home economics teachers 
and is available free of charge at the Technical Information Center at Oak Ridge, Tennessee.

This particular document covers a number of items, including food purchase, storage, preparation and clean-up activities.

Although this publication was developed primarily for home economics courses, a broad audience seems to have found this document to be of use. Another publication that has been developed is called "Residential Energy Educational Program." This was designed to educate the residential consumer on all aspects of energy conservation applications, through a multimedia approach.

For example, TV, radio, audio/visual presentations and these kinds of things. This particular program is in the material development stage and we are going to be working on the testing and evaluation stage. It is being done in cooperation with the Tennessee Cooperative Extension Service.

We are also developing a publication called "Instructive Materials for Secondary and Vocational Schools." This relates to residential and small commercial applications and w111 be prepared within the next few months.

We hope to continue to develop these kinds of publications and we know that we have not covered the entire waterfront. We are hoping that we can determine other meaningful and effective programs in these areas. 
of course, resource constraints always limit the amount of these kinds of projects that we can work on and we look for any information or any suggestions any of you may have.

MS. HOBSON: Okay. Thank you, Mel.

We will come back to you, Weldon, if you don't mind, with question No. 7 in your program.

Question No. 7: In looking to the full range of solar and renewable energy sources--solar heating and cooling, composting of animal and crop wastes, methane production, alcohol production and use, conservation measures, low-head hydro-, wind power, as well as combined systems--is DOE prepared to fund and coordinate an effort that would lead to increased energy self-sufficlency for the farm communtty? I think it is appropriate that the Department of Agriculture answer this.

DR. BARTON: We are pleased to participate on this panel this morning. We recognize, of course, that our primary mission in the executive branch is agriculture and food and rural development. Although we have substantial activities in the energy area, these revolve around our predominant responsiblltties in rural development, food and agriculture.

In the Department of Agriculture in fiscal year 1978, about $\$ 47$ milion of the Department of Agriculture Budget will go into activItles that have energy impact. Of those 47 million dollars that go into energy activities, a little over $\$ 9$ million is pass-through money. Over $\$ 5$ milition of this pass-through money, about 5.3 million dollars, comes to the Department of Agriculture from the Department of Energy. For the most part, these are not discrete energy functions per se. They are activities in agriculture that have an energy component. 
Let me comment on question No. 7 , with reference to our implementation of Section 1420 of the Food and Agricultural Act of 1977.

Under section 1420 of the 1977 act, the Secretary of Agriculture is mandated to carry out a program of pilot projects to convert grain, wood products, and other agricultural commodities into industrial hydrocarbons and alcohols for fuel use. Specifically, the Secretary is required under Section 1420 to fund, through guaranteed loans some four pilot projects, up to $\$ 15$ million of guaranteed loans for each pilot project. We are required to fund projects only if they are found to be economically feasible, and only if they produce a positive net energy input/ouţput ratio.

We are moving ahead with the implementation of Section 1420 . We published proposed regulations in the Federal Register on May 12. A series of hearings on the regulations will begin tomorrow here in Washington, D.C. Field hearings will be held June 1 in St. Louis and June 3 in Spokane.

DOE 1s, of course, participating with us. The Department of Energy will be represented on the hearing panel tomorrow.

There is no question that it is technically feasible to convert agricultural commodities into alcohol. The question is whether it is economically feasible, and economic feasibility will depend upon very site-specific factors. 
It is more likely to be feasible if we use residues; crop residues, animal residues, wood residues, than if we use the finished grain such as wheat or corn. It is more likely to be feasible if those residues are already collected, if they are in concentrated feed lots or at sawmill locations, so that you don't have to incur the cost of collecting those materials.

The process is more likely to be feasible if you can piggyback on an existing boiler fuel source such as waste heat from a utility. company, or if you can provide the boiler fuel for the manufacturing process directly from the feed stocks themselves, thus minimizing boiler fuel costs.

The workabllity of projects to convert agricultural commodities Into alcohol production under Section 1420 depends upon very site specific factors that relate to the individual farm or area where the project is located. And the success of other solar and renewable energy sources referred to in question 7--solar heating and cooling, conservation measures, and others--likewise must be tailored to the local situation.

The Department of Agrlculture, with its State and local delivery system of the Cooperative Extension Service, Farmers Home Administration, Agricultural Stabilization and Conservation Service and other agencies, has the capability to expedite and assist the application of these solar technologies on a localized basis. We are prepared 
to work with DOE, in an expanded role, to accelerate the application of solar technologies on farms and in rural areas.

[Bell rings.]

MS. HOBSON: I hate to ring the bell calling time on a guest. Please forgive me. Maybe we can come back to this subject a little later. We do have to move on.

Let's go'to the next DOE person. Doug, you are going to answer question two, which is, of course, a very easy question. I will read it:

"In recent public policy debate on the expenditure of energy within our 'food system,' on-farm technologies seem to have recelved a disproportionate amount of attention. In the future, will other segments of our 'food system' (manufacturing and processing, transportation, wholesaling and retailing, out-of-home preparation, and particularly in-home buying, storage, preparation, and waste disposal) be receiving DOE attention more nearly in proportion to their actual energy expenditures and potential energy savings?"

MR. HARVEY: Yes. Since Tina has a Major Bowes gong up there, I have prepared a rather long answer to this question which I can't possibly cover, so rather than do that, I would rather informally cover It for you, but the complete text will be in the transcript that will be provided to you at a later time.

In 1976, the United States consumed on the order of 72 quadrillion BTU's and they were consumed basically in four end use sectors. The transportation sector consumed about 28 percent of that energy. The residential sector about 22 percent. The commercial sector about 13 percent, and the industrial sector about 37 percent. Now, these end use sectors are exactly how the Assistant Secretary for Conservation and solar applications has organized the conservation activities. 
We have major divisions in transportation (in application to the food industry they are developing higher efficiency heat engines and electric vehicles that potentially could increase the energy efficlency of fuel in the transportation of food and of course a11 other commodities, and passenger vehicles associated with the transportation sector). In the Division of Buildings and Community Systems, Dr. Chiogioji has represented some of the work that they are doing, but they are developing higher efficiency appliances for residential and commercial use. They are developing test procedures in labeling appliances such that the consumer will know what the energy consumption of those appliances are. And they are developing new technologies specifically applicable to the commercial sector of the restaurant business to improve the efficiency of restaurant food preparation and perhaps later Dr. Chlogioji can elaborate on those points.

The objectives of the Division of Industrial. Conservation, of which I am in charge, are to examine the food industry, as well as other industries, in great detail to examine how we can determine or develop technology that would significantly improve the efficiency of energy use.

That is reduce the direct consumption of energy in the production and preparation of food stuffs in this case.

The food industry is an extremely fragmented industry, and I would just like to make a point that there is something like 28,000 food processing activities or firms that contribute to the food industry. 
Now, these firms have been using technologies that have. evolved during a long period of low energy costs and abundant energy supply.

That technology allows them to take a product like tomatoes, for example, that is available only three or four weeks out of the year, process it very quickly and in a known fashion. They know they are going to get an acceptable product and can ship it out to the marketplace.

Most of those companies have no research facllities at all. There a few that do, but the development of new technology for the processing of food is one where the Federal Government can play a very . significant role and, believe me, there are tremendous opportunities ava1lable.

Dr. Mayer mentioned several of the food processing industries He mentioned beet sugar, for example, which indeed is one of the most energy-intensive processing activities in the whole food processing spectrum, consuming on the order of 80 trillion BTU's annual1y.

The processing of sugar is one primarily of evaporating water, and when you evaporate water it costs about 1,000 BTU's per pound of water evaporated.

Our approach to this problem would be what other techniques can be used to concentrate the syrup, such that sugar can be precipitated out pure, without going thorugh this thousand-BTU per pound. Such 
technologies as electrodialysis, reverse osmosis, and freeze concentration could be applied, but never have been applied to the beet sugar Industry; or the citrus concentration industry, or the textile industry, as a matter of fact.

This is the approach which the Division of Industrial Conservation is taking. There are ample opportunities for the savings of energy and we belleve by the demonstration of new technologies (which industry will not be able to pursue on 1 ts own because of the risk assoclated to developing the technologies), we will be able to demonstrate a far more effective, less energy intensive food processing change.

Thank you.

MS. HOBSON: Thank you, Doug.

All right, Earle, I think you are getting a very interesting question. It is something that our public interest groups brought up which I was not aware of. Having had the privilege of working with you for a couple of years, I know that you know about these things. You have question No. 9;

"Approximately 75 percent of the anhydrous ammonia produced was consumed by the agricultural industry. Since some ammonia is found in the chemical reactions taking place in the coal gasification process, it seems reasonable to suggest that a process could be designed to optimize the direct production of ammonia. Does the Department of Energy R\&D effort on coal gasification include projects to develop methods for producing the anhydrous ammonia that is so vital to agriculture in the U.S. and developing nations?

We also understand that nitrogen fertilizers can be made from alcohol and that leguminous plants and free-living, nitrogen-fixing bacteria can reduce the need for anhydrous ammonia. What is being done about this?"

MR. GAVETT: Thank you, Tina. 
The Department of Agriculture is concerned about fertilizer and the use of anhydrous ammonia for a number of reasons.

First, it uses fully a third of the energy in the agricultural production process. We are talking about 3 percent of the Nation's energy use. So, roughly, about one percent of the Nation's energy use is for the fertilizer function and it is largely anhydrous ammonia nitrogen fertilizers.

It is essential because $1 t$ is the one largest productive input that the farm uses and, while many of us would like to see the farmer back off in using so much natural gas in the form of nitrogen fertilizers, as an economist the farmer has to use this.

He is getting a very good return for the last dollar that he uses of fertilizer. He is probably getting on the order of two to three dollars in return for it. So, economics would suggest that he continue to use it and use it more abundantly than the other resources. But, by the same token, the Department is concerned in trying to reduce the amount of fosstl fuel energy that is used in agricultural production, and so $I$ wi1l address the rest of my comment to that.

The Department has since its inception been interested in working on crop varieties. One of the principal functions is to improve crop varleties, including legumes. And we have bred alfalfa and clover to be winter hardy, drought resistant, to have higher protein content, and be more digestible to animals. 
We have also assured farmers that their legumes will be soll-enriching, so that nitrogen will be put into useable forms by the plants. But recent research by the Department focused on legumes includes making sure that legum̈es do produce nitrogen, and not all of them possess the same capabilities.

In a study of alfalfa clones or plants in Minnesota, it was found that these leguminous plants had the abllity to fix nitrogen in an astonishing range--from 15 to over 200 pounds per year. Just imagine the difference; 15 to 200. Think of the poor farmer who put in legumes with a predominant mix of plants capable of producing 15 pounds and he is counting on free nitrogen from the air. He is going to be sadly disappointed. So researchers are trying to phase out these barren and lazy nitrogen-fixing plants. We have this tremendous opportunity to Improve the ability of these plants to fix atmospheric nitrogen.

In addition, the Department has been working with land-grant institutions in trying to come up with different varieties of legumes; some varleties that do not take out of production land for a whole season or a year or for a number of years, such as alfalfas and some clovers do.

I am speaking in terms of such things as winter vetch, which can be planted at about the time the regular crops such as corn are being harvested, and then that particular varfety or type of legume will grow in the fall, in good days of the winter, and in early spring, and then could be turned under as nitrogen fixing plants for the nitrogen to 
be used in subsequent plants, and not keep this land out of production, only perhaps for a few days longer.

There is great potential here and, while you don' $t$ get as much nitrogen per acre, something on the order from 0 to 70 pounds, depending on whether the vetch winter kills or not, there is a significant opportunity here, particularly in the Southern States.

Much work remains to be done, and the Department of Agriculture is pushing forward to make certain that this area is covered.

Thank you.

MS. HOBSON: Thank you very much.

Dr. Mayer, I think you have an opportunity here before our coffee break to make some comments on the questions as they were answered.

DR. MAYER: Well, I will concentrate particularly on questions No. 2 and No. 4 which are particularly important from the standpoint of nutrition and food, particularly Mr. Harvey's answer.

There are three areas that trouble me. It is obviously necessary when looking at a complex system like the food system to divide the problem into something manageable. But the DOE has chosen to do it on the basis of this so-called end use classification, which is a perfectly reasonable way to approach it from one viewpoint, but which absolutely needs to be complemented by a look at the interrelationship between the various end uses. 
For instance, to give one example: Food can be cooked and prepared by industry or they can be cooked and prepared in the home. There is obviously a trade-off between the two. Somebody is going to cook the piece, either the Green Giant or Mrs. Smith. One of the questions we are interested in is what is the interrelationship and as I have already indicated in my talk in some cases it is more effective to have industry do it.

In some cases, it is more effective to have Mrs. Smith do it - in terms of energy efficiency. You have to look at it almost case-bycase.

Secondly, you alşo have to look at the cholces and not just at the single most effective use.

I am not one who wants to dictate food cholces to the American people. It is useful, however, to note because it can be important in the case of emergencles that for a protein of equivalent quality, you are going to spend six calories per gram of protein if you use herring and you are golng to spend 800 calories per gram of protein if you are going to use feed-lot beef.

Now, I am not requesting that we replace beef.

MR. HARVEY: I hope not.

DR. MAYER: The point is that, in that range, there are enormous differences in beef as prepared in various ways and these have to be looked at. 
A second problem I think with the DOE approach is that the process itself is not the sufficient method of analysis. I don't know of any corporation in the United States or any organization, and that Includes universities and hospitals that I am responsible for, which have not appointed one of the brightest young managers to be the energy conservation manager, and report to the chief executor. I think all corporations are trying to reduce their energy costs, and it is quite proper for DOE to help with this, but to a large extent it is a process that would take place without Government assistance. Anyway, I think that all of us who have looked at energy costs know that the analys 1s of a single process is not enough. To give one example, in our studies of the energy costs in the United States, one of the companies that make frozen orange juice' told us that the cost of the process was a minor factor as compared to the way in which the machinery was utilized because if they have to freeze once a week as they do at certain periods of the year and then warm up instead of letting the machinery function on a continuous basis, they get entirely different energy costs. And this, we find, is a very common problem in industry; that is, the extent of capacity at which the industry is running.

A third problem, if I am not mistaken, is that this method does not look at secondary influence. In some cases, those can be considerable. For Instance, in the case of the flshing fleet, the cost of making the equipment and the boat can be as great as the energy costs of fishing itself. 
So what I am saying is by no means meant to be criticism of what DOE is doing in itself, but it is to emphasize the fact that there is a need for an additional study which takes the end use as one of the factors considered and which complements the approach.

With question four, I was very much impressed with what was being sald in terms of the development of educational materials. What does bother me though is that in many cases, the figures we most need do. not exist. So that what I would simply make is a plea for additional research in the energy cost of the food system so that we can get the figures which we need to help people make choices.

One area where education is obviously needed, and information does not exist, is in the case of home waste. We need better figures on waste because if the whole cost of the food system is included in the food on the table and we end up not knowing how much of the food is wasted and how much could be saved, we obvlously are deluding ourselves. I know of some examples of, say, certain school lunch programs, and certain Army and Air Force bases, where figures exist and represent an enormous proportion of the total. The waste in restaurants is enormous, and one might look at some of the legislation which exists as well as some local ordinances which, in fact, increase the waste without necessarily doing much for the sanftary protection of the public.

And, flnally, I think there is a need for an enormous degree of education in that area, and it ought to be undertaken. 
MS. HOBSON: Thank you very much. We know that nobody here today is criticizing DOE; you are just offering suggestions, right? We understand that.

There is a difference.

Now, we are going to take a coffee break for about 15 minutes. Please write your questions on those cards and talk to our staff at that table in the hall to get a number. Everyone will have a chance to ask their question today of the panelists. Also, when you come back, please sit toward the front so we can conduct the session a little more informally than perhaps we have been. I think that will be more interesting for everyone.

We will see you back here in 15 minutes.

Thank you.

[Short recess.]

MS. HOBSON: I think we are ready to start.

This is how we usually conduct the discussions; I have some names of people who signed up to ask questions. They will be called on first. Harry and John in the back of the auditorfum have hand mikes. If you don't want to be on the 'videotape you can just raise your hand and Harry or John will come down and hand you a hand mike to use in asking your questions.

We run it like a presidential press conference. That is; you have a question and then you get a follow-up if the panelists did not answer your first question adequately. 
. If you do want to be on the videotape--which is often requested, particularly by universities, then you have to come up here and you have to sign your life away on a card which says that we can have you on the videotape.

Also, we have some fine resource people who have been working on the answers to the questions and who are in the audience. I w111 call on Gloria Hamilton for the first question. She is with the Bureau of Science Research.'

We will hand you the microphone and then, when' you have finished your question, hand your card to Harry so that we have it for the record.

MS. HAMILTON: I am perhaps showing my own bias, since I represent a survey research organization, but it appears that many of the issues which have been discussed today could be clarified or delineated through the use of surveys to find out how the general public feels, their attitudes towards energy conservation, as well as targeting some of the subject areas in the energy picture, where the public needs more information and education. Is any such program of research ant1cIpated by DOE?

$$
\begin{aligned}
& \text { MS. HOBSON: Or the Department of Agriculture? } \\
& \text { MS. HAMILTON: Right. } \\
& \text { DR. CHIOGIOJI: I can perhaps give you a little bit of infor- }
\end{aligned}
$$

mation. We don't do a lot of survey research, however, our particular program is funding an organization called Cambridge Reports that is doing a number of surveys for us, attitudinal type surveys in relation to energy and energy problems, focused on the buildings and community systems area for energy conservation. That is the only program that we have that is ongoing. 
I don't know whether/Doug has anything going.

MR. HARVEY: Not surveys of consumers specifically, but we are doing a lot of general overview analysis. For example, we have developed something called agrimod which is a model of the agricultural food processing universe that looks at the interrelationship of various food processing and production activities in terms of their energy consumption and targets, those most energy consumptive activities for research development and demonstration programs.

MS. HOBSON: Okay, Jean, do you have a program on this one? DR. MAYER: No, I don't except to say that I think that it is obviously extremely important to both know better what the practice is with the American people and the reasons for their choices and the factors that would influence their choices.

I know there are many people who have a somewhat pessimistic view of the way in which soclal change can be accomplished. I don't share this view. I think that when the message is clear and when there are acceptable and economical options avallable, the American people are likely to change very rapidly once they understand clearly.

One clear example is the way in which people went away from fluorocarbons for reasons as remote as damage to the ozone layer, as soon as the information was available.

MR.-HUGHES:-I would-11ke to just comment on this in very. general terms. 
We, in the Department, have sort of a priorities problem. There has been a feeling, in at least some quarters, that the survey business has been overdone. I am not sure that we in the Department collectively agree with that, but there is a fair amount of evidence of lack of public understanding of the nature of the problem or, in fact, that there is a problem, which suggests that perhaps we are not only behind in our utilization of surveys, but behind in our capacity to communicate the basic information necessary before people can respond to the surveys intelligently, and obviously my office is concerned about this.

We are trying to communicate as much as we can about the problem. Dr. Mayer referred to public reaction to the fluorocarbon publicity. That kind of focus is very difficult to get in the energy business. A substantial part of the country and substantial groups of the public have not gotten that kind of focus, so we have that work to do also. But we do need to know, I certainly agree, more about public attitudes on many of these questions.

MS. HOBSON: Thank you, Sam.

DR. BARTON: I might add one thing on that.

At the Department of Agriculture, we have not had systematic surveys focused specifically on the topic referred to, but we do get input through the extension activities and the research laboratories of the Agriculture Department that are scattered across the United States 1n, I suppose, every county of the United States. We depend upon the 
feedback that we get through these localized agencies, particularly, I think, in this area of solar and biomass dispersed where the problems tend to be as localized and dispersed as our fleld offices.

MS. HOBSON: Earle?

MR. GAVETT: One set of studies is ongoing in the USDA's

Economics, Statistics, and Cooperative Service Consumer Panels survey. These are periodic surveys that have, at one time, addressed the energy used in homes and some aspects of food, but it is not sufficient.

MS. HOBSON: Miss Hamilton, do you have any follow-up on

that?

MS. HAMILTON: No, thank you very much.

MS. HOBSON: Let's go to environmental; Garry DeLoss.

MR. DE LOSS: I have a question for Mr. Barton. Could you compare the cost of alcohol fuel to biomass sources and to a variablesource material?' Will you use the grain proper or will you use the crop residues?

My question 1s; when Secretary of Energy Schlesinger comments that the cost of ethanol fuel will be $\$ 90$ a barrel as opposed to $\$ 30$ a barrel for methanol from coal, which biomass is he assuming; the finished grain or the crop residues?

DR. BARTON: I am not sure what he is assuming. In our proposed regulations under Section 1420, which I referred to earlier, we defined "agricultural commodities" as synonymous with biomass generally, so that you could use as feedstock anything from crop residues to animal waste to wood waste to corn and wheat. There is a tremendous range in conversion costs depending upon what you use as feedstock. 
I think probably he is referring to using the finished grain as the input, which is the most energy-intensive feedstock.

MR. DE LOSS: We11, we also suspect that it is because it makes ethyl fuels less cost-effective if you use this highest-cost source, and the underlying question is; is he loading his answer by assuming the worst case, and that is what I suspect. I wonder if maybe the Agriculture Department and the Energy Department could get together and give us an answer in the transcript on this? Maybe we could see a range of ethanol -fuel costs depending upon the source material.

DR. BARTON: Let my say, in fairness, that there is some support in the Congress, particularly where you have surplus grains, for using grain as an input. It is a broad interpretation of that legislation that we have proposed in our regulations.

MR. HARVEY: I think we ought to embellish on what we have a bit. But let me comment for one minute on your question. If you go to fermentation of grain which has a falrly high sugar content, the fermentation process is relatively inexpensive. The feedstock is very expensive. That will give you the kind of prices Dr. Schlesinger talks of. If you go to stover, which is the stalks and the junk that comes out of, let's say, corn production, then that has a very high cellulosic content and you have to go to a process known as enzymatic hydrolysis, which is a very expensive process. Though your feedstocck costs go down, your cost of process goes up, and it is much longer. So, there is a tradeoff that has to be made and I can't give you the exact figures of the range 'right now, but it still is not a very cost-effective process.

MR. DE LOSS: I suspect, though, that Dr. Schlesinger has

chosen to use the high end of the range. 


\section{MR . HARVEY: Possibly.}

We will find out the details of the economics and give them to you in the transicript.

\section{STATEMENT FOR THE RECORD:}

Methanol and ethanol are each derived from different blomass sources, and have different levels of energy efficiency. Methanol is largely produced from coal, wood, or crop residues. Its costs range between $40 \notin$ and $50 \notin$ per gallon or approximately between $\$ 5.50$ and $\$ 7.50$ per million Btu. Ethanol is produced from grain or sugar crops and has a higher production cost. Estimates range between $\$ 1.00$ and $\$ 1.30$ per gallon, or between $\$ 12.00$ and $\$ 20.00$ per million Btu. Ethanol is a more efficlent fuel source with $2 / 3$ the heating value of gasoline, while methanol has only $1 / 2$ of gasoline's heating value. The heating equivalent of a barrel of oil from methanol and ethanol, respectively, would cost $\$ 30-\$ 42$ and $\$ 67-\$ 112$.

The variance in cost estimates allows for differences in production plant capacity. The larger plants could produce the alcohols for less due to economies of scale.

MR. DE LOSS: On a related point, which came up yesterday in a meeting involving the domestic policy review of a solar energy program that all of your agencies-are going to be involved in, we were interested in getting the Alcohol, Tobacco and Firearms Bureau of the Treasury Department involved, because they seem to be retarding development of the decentralized production of alcohol fuels: 
MR. HARVEY: It does not have the right label on it.

MR. DE LOSS: It seems to me that, over recent years, they

have made it much easier fór people to produce their own wine at home.

MR. HARVEY: Two hundred gallons a year.

MR. DE LOSS: And perhaps they could find a way to accommodate the production of alcohol fuels on this extremely decentralized basts.

DR. BARTON: I might mention that Treasury is--going to be testifying at our hearing tomorrow on this point. As I was emphasizing earlier, if this kind of conversion is going to work, many factors are involved. These include the kind of feedstock, the kind of fuel, the kind of market you have for the industrial hydrocarbons and the byproducts that are produced. It has to be put together right, on a site-specific basis.

There is no substitute for that.

MS. HOBSON: Jean?

DR. MAYER: I would like to make a comment recognizing that there is a difference between, learning certain things and then deciding that it is economically important to do them in the United States at a particular time.

Let me give you an example. During the War and the occupationIn France, cars and trucks functioned normally on gas produced through the combustion of wood. They had a very cumbersome attachment which enabled them to burn the gas to turn the trucks. It was not an economIcal system under normal circumstances and, when the occupation ended, 
the systems were dismantled and the trucks went back to burning gasoline. But it was necessary when there was no alternative.

Now, we have a lot of countries at this point the welfare of which we are concerned with and which don't have any foreign currency with which to buy petroleum. It may be necessary for them to use biomass material because, in effect, they have no choice, even though from our viewpoint this is not an economic process.

I think it is essential that we have a variety of options even though it is quite obvious that, in the foreseeable future, we would not use them.

MS. HOBSON: This question is asked by so many individuals and public interest groups that I think it is worthwhile, as Sam suggests, that we have a full answer in the transcript; hopefully coordinated. between Agriculture and DOE.

Let's move on and we. will try to answer a little bit more rapidly.

Don Meyer is next, and would you please identify your organization?

MR. MEYER: Yes, I am with the Vegetarian Information Service. Your energy conservation program has been addressed to the improvement of efficiencies in present energy use.

Now, should these improvements prove not sufficient, some energy-consuming activities will have to be curtailed. Has DOE begun to identify those activities which consume significant amounts of energy and which, like the production and consumption of cigarettes and feedlot beef, result in major national health problems? And, if so, what plans have been made to inform and consult with the public during this process of Identification? I noticed this morning that, when Dr. Mayer said 
that he was not interested in commanding you to reduce the production of feedlot beef, someone on the panel saying immediately, "I hope not." This leads me to another question.

Will you allow your priorities to limit our future options?

MS. HOBSON: Good question.

We are talking about contingency plans, Jean.

DR. MAYER: I said beef. I did not say feedlot beef. I think there are very good reasons, in fact, there are essential reasons, from a health viewpoint for the Nation, which would command that we either decrease our consumption of beef or decrease our consumption of heavily saturated fats, and indeed it is beginning to happen fairly effectively. On the other hand, you have to remember that when you talk about the beef industry, you are talking about two entirely different segments. The feedlot beef is extremely expensive from an energy . viewpoint with a weight of conversion of calories of corn to calories of beef of no more than about 7 or 8 percent as compared to, say, 25 percent for milk or 25 percent for eggs.

But, the range-fed beef is by and large noncompetitive with other sources of human food and is making use of grass and other disbursed material which would not otherwise be used for human consumption. So, I think there is a very strong case for a reduction in the fat content of beef, both from the polnt of view of energy-saving and from the point of view of health. And I think it is beginning to have an effect. The elimination of the consumption of range-fed beef, on the other end, would have to rest on entirely different premises. 
MS. HOBSON: All right, any other panelists?

MR. HARVEY: I guess I had better answer because I am the one that showed prejudice because, frankly, I don't like the, Idea of charcoal broiled herring, that is all.

Yes, I guess I am prejudiced and I do feel that the Government should not be dictating in any form a diet for the consumer of the United States.

I think the consumer should be well informed. I think. we , ought to be working on processes that reduce energy consumption. I think Dr: Mayer's point of allowing the consumer to be informed about the energy content of various foodstuffs is an extremely important function.

As a matter of fact, the Joint Council on Food and Agricultural Science has adopted a program that will, indeed, evaluate the nutritional value of various foodstuffs and their energy consumption.

I think that is very important. I think it is important that the consumer be informed, but I have to admit that I am prejudiced against the United States Government ever dictating to the consumer what he will eat.

MS. HOBSON: Doug, would you tell us, since you do strongly agree that the consumer should be informed in terms of the energy content of foodstuffs, if your office is doing anything in that area? MR. HARVEY: Yes, we are doing something in that area. As Dr. Mayer is very well aware, Tufts University is doing a study looking at 
seafoods and the nutritional content thereof, as compared with other foodstuffs.

In addition, the recent passage of the farm bill indicates that the Department of Agriculture shall now have the lead agency responsibility for nutritional content of food.

Weldon, perhaps you would like to discuss that point, but from what I understand from the meeting April 28th of the Joint Council on Food and Agricultural Sclences, they are going to take on a major initiative in nutritional content of food.

DR. BARTON: We have a key role, I would say.

We are establishing in the Scfence and Education Administration a Human Nutrition Center, with headquarters in Beltsville, Maryland. We have several labs that are conducting research on the nutritional composition of foods, carbohydrates, and other nutritional cóncerns. There is a great deal of information being generated by the Department of Agriculture on nutritional content and the relationships between diet and well being.

We agree that the primary emphasis should be placed upon provision of information, and that to attempt in Government to step over the line to dictating consumption patterns would probably be counterproductive.

I think that producers get cues from consumers as to the type of foodstuffs that are desired. We have trended toward leaner types of beef, swine, and other meat animals. 
We are certainly moving generally in that direction. Dr. Mayer in his study found that, if you put this in terms of energy intensiveness, the collection and harvesting of lobster is as energyintensive as feedlot beef. We don't want to get into the business of saying to consumers that they should not be eating lobster.

MS. HOBSON: I think we are talking about just giving the consumer information.

MR. MEYER: I think the major point of my question was not, addressed at all. .

Now, Mr. Harvey, in response to my question has pointed out that he does not want to dictate to the American consumer. I agree with him. I don't think any of us in this room wants to dictate to the American consumer, but if we don't have enough energy, is the Department prepared to establish priorities of energy usage? How is the public educated, informed and consulted about the formation of these priorities, whether they be about feedlot beef or sugar or what?

MS. HOBSON: Sam, correct me if I am wrong, but I think right now we are in the process of preparing a contingency plan for the situations you have described, and I think my office has been asked to review it and to get public comment--which we will do in terms of the overall energy contingency plan. So I will be happy to get back to you with information on that.

MR. MEYER: Thank you.

MS. HOBSON: Jean, you had a point.

DR. MAYER: Let me start out by saying that I completely agree

that we need to have a system of contingency planning because we are really:having two problems, on the one hand a very long-term shift in 
energy consumption and an increase in the effectiveness of the various processes for which it is used.

We also ought to have contingency planning for real emergencies and the answers are not necessarily the same for both cases.

I want to go back to the problem of energy use. There is obviously the press and various people have picked up on the study we have done in the case of lobster and made it appear as if we told people not to eat lobster. Nothing was farther from our minds. Particularly since the consumption of lobster is such an infinitesimal amount of the total food consumption in the United States.

It was just an example of the fact that, as Mr. Barton said, you can.have extremes in differences in range of energy use for some things classified as "seafood."

On the other hand, if you look at the fact that people like lobsters, and like shrimp, and that those, Indeed, are very high in energy cost and very high in cost period, this consideration leads one to think that the marginal profit exists there both in terms of money and energy use, and that this would be a particularly interesting type of aquaculture to develop. Indeed a number of organizations are, in fact, working on those plans, together with such accessory aspects as the use of solar energy, the use of waste, effluent water from nuclear plants, and so on; to develope just this type of Industry which would be possible if its total costs and its energy costs, as it is practiced now, were not so high. 
MS. HOBSON: Thank you.

DR. BARTON: I am no economist, but the economics of this are awfully tricky. The Department of Energy is now developing a standby gasoline rationing plan. I hope to God we never have to implement that kind of plan because the economics are awfully tricky and it could be counterproductive. We must keep economics in mind, as well as energy.

MS. HOBSON: All rlght, we are going to have to move on a little more quickly now, but the panelists will have a chance to add to the transcript.

James Hyde, Grocery Manufacturers of America.

MR. HYDE: I think I can talk right from here.

I have a built-in microphone. I have more of a procedural question. I am with the Grocery Manufacturers of America and we have various calls at the last minute inquiring what publicity had been given to the holding of this meeting. Had the notice of it been pub1ished in the Federal Register? Since we consider industry to be energy consumers, I wonder why those engaged in the energy conservation reporting program were not notified of the meeting.

MS. HOBSON: What we have done with the six briefings, which represent our inftial effort to see how we could best get out information, is that we especially invited the members of the Food Industry Advisory Committee and our advisory committee, the Consumer Advisory Committee. Then we put a notice in the press. A press release did.go out to all newspapers, etcetera. We notified consumer and public interest groups in town. 'We are happy to have the food industry here and if you feel that there is a better way of advertising these meetIngs, we would be delighted to do 1 . 
MR. HYDE: We do feel there is a better way.

MS. HOBSON: Would you like to get together with me afterwards and you can give me some clues?

MR. HYDE: I would be happy to.

MS. HOBSON: All rlght. Thank you.

We are delighted to have here today a member of the FDA Food

Industry Advisory Committee for two years, and who's come back from

Kentucky. He is the second on our environmental 11st; Al Fritch. Al is going to speak for that committee as the consumer member who served on the committee for two years. So, we will permit Al two questions.

MR. FRITCH: The first question will be about the Food

Advisory Committee's recommendation that it made to the FEA. Two years ago, I think it was, in Chicago.

MS. HOBSON: Yes.

MR. FRITCH: And that is listed as question No. 1 here on our questions that were passed out.

The first two of the six areas were not voted in favor. They got a minority vote, but it was almost a lineup of industry against consumer when it came to that, so I still feel, as a consumer and environmentalist, that they should be answered. To some degree Mr. Harvey touched on those. But the other five I am not sure have been answered at all.

I repeat the question that was asked by the person who wrote this. Why were none of the projects funded when simflar industryoriented FIAC contracts, such as conservation projects for grocery stores and restaurants, were funded and published?

MS. HOBSON: I would like to say that the FEA Consumer Advisory Committee did support all six projects and requested a focus on 
food and nutrition. The request here was for studies showing what was being done, what had been done, and how good the existing data was in all of the six areas. They wanted spectfic reports, such as energy use in the food system, on all six of those specific areas.

Doug, I guess it is your turn.

MR. HARVEY: I guess so.

As I read these questions specifically, they deal with energy and nutritional content, energy conservation of food system packaging, energy waste through food waste due to food systems inefficiencies, recycling, resource recovery, equipment efficlency, labeling, and energy efficiency guide for home food preparation. Among those recommendations, the committee did not propose studies, as I understand it, in energy use and nutritional content, energy conservation and food system packaging.

MS. HOBSON: The Food Industry Advisory Committee did not, and the Consumer Advisory Committee did.

MR. HARVEY: I see.

I just mentioned some of the work that we are doing in nutritional content with Dr. Mayer. There has been work done on the food system packaging survey, if I can remember the answer to the right question.

Larry, do you remember the right question where we mentioned that report that Commerce did on packaging, energy use and food system packaging? There is a report out on that subject. We w11l find it for you in a second. 
In September of 1976, the Department of Energy published a detailed study of beverage container deposit legislation entitled, "Energy and Economic Impacts of Mandatory Deposits." The study concluded that the results of a national beverage container deposit law will be determined by changes in consumer behavior, 1.e., what types of containers they will purchase and how of ten they return those containers for recycling or reuse. The full study is 750 pages and can be ordered in papercopy or microfiche from:

\section{U.S. Department of Commerce National Technical Information Service (NTIS) Springfield, VA 22161}

The order number is PB 258638-AS. An 18-page executive summary is also . available; order number PB 258637-AS.

Energy waste and food waste due to food system inefficiencies. We are looking at somé potential programs for recovering food waste material as food.

Now, there is a good deal of question as whether, for example, restaurant waste is indeed waste materlal because to a large degree such wastes are sold in the marketplace as swine food and various animal foods directly.

There is also a problem of blological vectors associated with the reuse of food sutffs that have to be very carefully considered. You don't have to worry too much about biological vectors in swine.

We are looking at a potential program for recovering food waste in protein form that has been processed such that the biological contamination is reduced and tt would be used probably for pet food. 
Recycling resource recovery and waste reduction. The Department of Energy, Office of Energy Technology, has an extensive fuels from biomass program to investigate utilization of agriculture, forest and animal residues to produce some sort of fuel. It could be an anaeroblc digestion program such that the methane is produced. It might be some type of grind and pelletizing program. All of these aspects are being investigated. Food system equipment efficiency and labeling as Mel pointed out, we have a program on appliance efficiency and labeling. There has been an amendment to the National Energy Act that requests the Department. of Energy to develop labeling and test procedures for determining efficiency. That has not passed as yet and it is not within the purview of the Department of Energy to do so as yet. If that amendment were to pass with the National Energy Act, we would institute a program in that area. Energy efficiency guide for home food preparation, Mel, perhaps you can answer this better than I, and I guess that covers the major areas.

MS. HOBSON: Yes.

Al, I think the answer is that no, we at FEA and DOE have not done the recommended reports in those areas, but we have taken some action in some of the areas. Is that correct, Doug?

MR. HARVEY: Yes •

If you would like a revlew of the overall industrial program which, incidentally, does, not cover all of these questions, but the overall Industry program, we have on the back table a draft, and please 
consider it a draft, of a report that outlines our program in great detail, and perhaps it will give you a lot more information.

MS. HOBSON: All right. Thank you.

Al, your next question?

MR. FRITCH: Is there work being done on comparative energy inputs for various home gardening techniques? We have a very small amount of gardening going on in our region of the country at this time. We would like to see the Government begin to encourage people once again to go back, as an entire country, into private gardening. Could we have some comparative energy values on that some time?

MS. HOBSON: Are we making any home gardening effort?

MR. FRITCH: That is question No. 6, to some degree.

MR. GAVETT: The Department of Energy has quite a good answer here. They indicate that, by and large, the energy used in home gardening is more than is required in commercial production and the Department of Agriculture generally subscribes to that. For the most part that is correct. In terms of cost-effectiveness, you'can't get a new dollar for an old out of a home garden. You do get a better quality of food. If you go out and pick a tomato or cucumber or ear of corn, you will get a much better quality out of the home garden. But, from an energy standpoint, you are not going to improve your situation by going with home gardening. This does not suggest that people should not do it. It has many other beneficlal advantages, such as getting out and getting exercise and fresh air, etcetera. But, from an energy sțandpoint, you are not going to Improve your situation. 
DR. MAYER: I think there is an important problem there which, I think, we don't have the governmental machinery to deal with in a sense.

In the past 30 years we have gone from a falrly laborintensive agricuiture to a capital-intensive agriculture with less and less labor involved. In fact, there has been a raptd decrease in the use of labor.

Now, historically, this is a process that has been going on all along; the people released from agriculture by more efficient farming systems then were absorbed by industry, and this is the way we built our manufacturing capacity.

In the past 20 years, particularly, it has not worked that way. The people who have been displaced through the increase in capital use and energy use in agriculture have not been absorbed in industry and are piling up in large cities, by and large on welfare.

We thus end up with a system which is much more efficient on a farm-by-farm basis. Mr. Jones' farm is much more efficient than it used to be as an effective money-making machine. But the efficiency of the country as a whole really has to take into account this very large number of people who are unemployed or underemployed, and who are no longer on the farm, and one arrives at very different conclusions as regards the efficiency per dollar, per acre, per unit of energy, depending on what particular system there is, and whether you are looking at the farm or at the country as a whole. 
I think that, in general, one could say that we would be better fed and probably we would see a lessening of some of our social problems, and probably effect some limited reduction in energy use if we developed legislation which encourages the maintenance of enough agricultural labor, the development of more production from home gardening, a decrease in the use of machinery as compared to the type of situation which we have had over the years and which has gone very much the opposite way.

MR. FRITCH: I don't feel the question was fully answered, because I was asking for comparative values. Even though Mr. Gavett answered that it perhaps costs more, on the average, in a home garden, I know that I have 600 square feet where I don't use a single ounce of energy except for my own physical body, and except for some seed packaging output.

I am convinced that this is an option among the 24 million home gardeners--to not use power instruments. For them this is very eff-icient, and this should be known.

MR. GAVETT: I would Iike to ask Dr. Charles Beer, sitting near you, to speak about the urban gardening program that the Extension Services initiated.

DR. BEER: I am not sure how much information you want on 1 . We have, following the instruction of Congress and the requests of people, established in 6 cities a year ago a pilot effort in urban 
gardening to reach the urban poor and, from that standpoint, it has been expanded to 16 cities this year.

This enables people to appreciate what they can do in the production of home fruit and vegetables. The figures that he asked for on the comparative information; we do not have any hard figures at this stage.

I believe, if my memory is correct, several universities are trying to put this together and also doing some research on organic gardening, but I can't quote that yet.

MS. HOBSON: Thank you.

We will add anything we can to the transcript. We have got to go on.

Ed Rothchild. I apologize, Al, but I do want people to get their questions in. Do you want to identify your organization? Foundation.

MR. ROTHCHILD: I am with the Energy Action and Education

The production, transportation, distribution and consumption of food have become increasingly energy-intensive, and as the cost of energy is forced up even more by the President's energy plan, this results in significantly higher prices. What is DOE doing to protect consumers from higher food prices caused by the President's higher energy prices? What study has the Department conducted or will it conduct with regard to the impact of higher energy prices on food?

MS. HOBSON: Doug?

MR. HARVEY: I tried to explain some of this earlier, but perhaps not in the right light. Obviously, in the whole food chain, there is some energy cost that represents an operational cost that 
contributes to the total price of the product that one buys and prepares in the home.

Without question, that energy consumption is some fraction of the total price of that food. Now, we have some very good detailed data on what fraction that is. For the average of the food industry, the cost of energy is on the order, as I recall, of about 3 percent of the total sales price of the food.

Now, the problem is basically this: If the cost of energy goes up, obviously the cost of food is going to go up. If we make the assumption that the cost of energy is going to rise faster than the inflation rate and other commodities, then indeed it will have a significant impact on the ultimate price of the foodstuff being purchased and that is of concern.

However, if one can simultaneously say that because energy costs have been low in the past and do not represent a significant portion of the selling price of the food, there has been very little incentive to improve the efficiency of that operation and if we can, indeed, find ways of significantly improving that efficiency, then we can reduce the energy cost content of the final product significantly.

I mentioned evaporation before because the evaporative load throughout the food industry represents on the order of 1.2 quadrillion BTU's, which is almost the total amount of energy consumed in the home preparation area, for example. 
If we could increase the efficiency of that function alone, let's say by 50 percent, and that is a very reasonable goal, it would significantly reduce the energy content of the foodstuffs being delivered to the marketplace and consequently, hopefully, reduce the $\cos t$.

I don't know if that completely answers your question. MS. HOBSON: Any other panelists care to comment? DR. CHIOGIOJI: I could perhaps give you a little bit more information.

I guess some of the programs that Doug has and programs that we have, kind of go around the question, but by the same token, also help to assist in the efficiency of overall energy usage, and, hopefully, reduces energy cost to the consumer.

In our program areas there are two particular efforts that in help. The first one relates to efficient appliances. We have a major project in which we are trying to determine what kind of techniques can be used to enhance energy efficiency within these types of appliances and we are hoping that these kinds of techniques will be incorporated in appliances.

In this area we are looking at things like refrigerators, freezers, ranges, ovens and things like this. In addition, we are working on appliance standards and labeling programs.

Perhaps Bill Walsh from the Appliance Program can give you a 11ttle more information on this area. 
MS. HOBSON: Mel, I don"t think we are answering his question. I think you are correct, and we do have more information, but I think we are not addressing his question because estimates are that food will go up as much as 22 percent next year.

What are we doing to examine the potential increase related to energy costs, the impact of that, and what are we doing about it?

MR. ROTHCHILD: That is much closer to what I was asking. I just want, before I get an answer to that, to ask about Dr. Mayer's statement that sugar production requires large amounts of energy. MR. HARVEY: Not only sugar, but throughout the food sector. MR. ROTHCHILD: Sugar is a large part of it. Since it provides no nutritional value, maybe we should not worry about it and eliminate it from the American diet. Maybe it would be more healthy for everybody not to have sugar and save a lot of energy.

of course, you have the sugar industry to deal with, and they would not be too happy.

MS. HOBSON: Is the Department of Agriculture doing any studies on the impact of higher prices of food to the American family? DR. BARTON: It seems to me that, in a number of these areas, we have been emphasizing research. Research is awfully important, but there are a lot of action programs that we ought to be getting into to try to achieve more energy efficiency. 
For example, in the transportation area of the food system, we waste a lot of energy because of the regulatory policles of the Government where we have restrictions on commodities and trucks.

We have Paul Mills here from our Transportation Services Branch of the Agricultural Marketing Service. I wonder if he might want to comment very briefly on what we are trying to do to shift regulatory policies that are energy inefficient?

MS. HOBSON: All right. Because of the number of people who want to ask questions, could I ask that you include a statement on that in the transcript? Could he do that?

DR. BARTON: Yes.

STATEMENT BY,MR. MILLS:

The Department of Agriculture maintains a transportation program which includes an advocacy role for agriculture and rural interests before decision making bodies in solving transportation problems, identifying issues, and providing input for policy determination. Activities involve transportation rates and services on farm and food products, which are undertaken to achieve gains in the marketing system, but which also produce energy gains in some instances, such as increasing highway size and weight limitations or eliminating unnecessary restrictions on truck backhauls.

As examples, we favor: 
1. Allowing truckers hauling exempt agricultural commodities under Section 203(b)(6) of the Interstate Commerce Act to haul regulated freight on their return haul.

2. Expanding the current exemption under Section 203 (b)(6) Include farm input items and all processed foods.

3. Revising the present 15 percent restriction on cooperative trucking for non-members to 50 percent in order to improve efficiency on backhauls.

We have also supported efforts to bring about greater uniformlty of State regulations involving size and weight limitations on the Interstate Systems and have advocated allowing the use of double traflers in States where not now permitted.

These are all matters which would improve marketing efficlency, conserve energy, and lower food prices.

MR. ROTHCHILD: And could I also ask if, in the transcript, you could be more responsive to the question I raised?

MS. HOBSON: We need to relate the answer to energy and food and prices.

MR. ROTHCHILD: That is right.

MS. HOBSON: So we are looking at a combination of the three. MR. ROTHCHILD: That is right. .

MS. HOBSON: Next we have Richard Cortright, consumer. MR. CORTRIGHT: I am with the National Education Association. 
My question is couched in terms of what we see as a decining interest in energy in the schools. We can see that from the marketability of our books. People are not interested. We feel that somehow in the schools we are over the hill where interest is concerned. In that context, I would ask this very simple question: What is your advice to schools with regard to serving fast-food lunches to.children, in terms of their costs and in terms of nutrition?

MS. HOBSON: Weldon, I guess that is yours.

DR. BARTON: Well, this presents a Catch 22 situation.

I wish we had Carol Foreman here to respond. There is a difficult problem of, on the one hand, maintalning participation by children in the school lunch program, and at the same time, trying to make those school lunches as nutritious as possible for the kinds who. participate in the program.

What our people are trying to do is to reduce that trade-off. That is, we try to utilize and emphasize types of foods that are attractive aesthetically and in terms of taste and compatibility to the children and, at the same time, compete with the fast-food chains for their participation in the school lunch program.

MS. HOBSON: How do you relate this to energy, Weldon? We are talking about food and energy here. Are fast-food lunches considered energy intensive?

DR. BARTON: Dr. Mayer might be able to address that.

DR. MAYER: One of the strong arguments of the fast food type of school lunch has been that they reduce waste and thus would be more 
effective. If you have figures as we have in some school systems, you have as much as 50 percent of the food wasted. Obviously this would reduce waste substantially. That is going to have an energy impact. The problem is that most of these programs are conceived to simply accept for the children whatever habits, good and bad they already have. I have made the point over and over that we should not be telling people what to eat, but I am not sure that even he would agree that this should also apply to the school lunch program where an educational function is, in fact, mandated by law to the Department of Agriculture.

I think the answer is a complex one. It also involves the teachers and principals taking a greater interest in the school lunch program than I am afraid is the case in many school lunch systems now.

In other school lunch systems, we tend to be very much more successful when the principal and the teachers are very much Involved. It reminds one of the sentence of H.L. Mencken, "To every complex and difficult question, there is a simple and easy answer, and it is wrong."

I think that the approach to improving the school lunch program is one which has to work on a number of fronts, but certainly as much as it improves nutrition and decreases wastes, it would have an energy effect. 
MS. HOBSON: Follow up?

MR. CORTRIGHT: Thank you, I appreclate the answer; which was a. simple answer to a difficult question.

I would think that perhaps this might be a small way to interest students and teachers (our members) in the energy problem, and we would appreciate the cooperation of various agencies involved here in getting that communication through, particulariy in terms of the inservice programs that were aliuded to earlier.

MS. HOBSON: We are glad you brought that up. Our office does deal with education, and we would be happy to meet with you to discuss it further.

I think it is a very good idea.

All right.

Industry; Brenda $0^{\prime}$ Grady.

MS. O'GRADY: I would like to address this to $\mathrm{Mr}$. Barton and Mr. Harvey, particularly. Have you found that the food Industry or the food system has made a definite effort to conserve energy? What types of projects is the food industry working on in conjunction with DOE to develop both new technologies and new processes that do conserve energies?

MS. HOBSON: Brenda, would you Identify your organizational

affiliation?

MS. O'GRADY: I am with the Grocery Manufacturers of America.

MR. HARVEY: As you. know, under the EPA Act of 1975, we have a reporting system for industry that reports on progress towards energy 
conservation using existing targets. We recognize that the reporting system developed under that act has several difficulties associated with 1t; which we are in the process of trying to correct. Based on the Information that we have accumulated so far, it appears that the food industry as an ent1ty (which, incidentally; is a very complex entity consisting of something like 46 separate four-digit SIC codes) has approached about 12 percent total reduction and certalnly approached about 80 percent of their goal for 1980 which I think is good progress. We wish we were able to determine exactly how that was obtained. I think we will be able to find that out. We are going to hold a series of meetings this summer to examlne how we can improve on this reporting sys.tem.

MS. HOBSON: Also, within the food system of four-digit codes, the targets range from about. 9 percent to 21 percent, and when you report on a two-digit. level, it becomes quite meaningless.

So, what we are saying is that we do believe that the food Industry has made an effort, but with the current data we have, we don't know how successful that effort is.

MR. HARVEY: Regarding new technology; Brenda; I think perhaps the document in the back of the room will give you some indications of those kinds of things we are concentrating on. There are some very lnteresting programs underway.

MS. HOBSON: Brenda, do you have a follow-up? MS. O'GRADY: No, that is fine, thank you. 
MS. HOBSON: Let's go on to Cynthia French; environment.

MS. FRENCH: I am with the Legion of Cars and Trucks. I want to ask if any work is being done to improve energy use in the two different approaches of pest control; integrated pest management and chemical pest management?

MS. HOBSON: And we may add, do we do any coordination with EPA on this?

DR. BARTON: Bob Yeck is here from our Sclence and Education Administration. Bob, could you talk about integrated pest management? DR. YECK: Briefly, we are looking at many different aspects of the pest management program.

We have within our organizing in the Science and Education Administration established a key thrust area on integrated pest management where we are setting up a program manager specifically for this type of activity. But, over the years we have had a very aggressive program towards avoiding the use of pesticides as much as we could through biological control processes.

We have had the radiated male techniques for screw worm control which has been very successful in the South. This program is now being moved into Mexico and the Mexican Government is cooperating with us, so it is a joint and international program now.

We do feel that we are going to have to have some pesticides in our package of tools which are going to work. We have other extensive programs on minimizing the amount of pesticides we would use. You are quite aware of those, $I$ am sure. Volume, precision applicators, pesticide application techniques and the like, so that we 
don't have residues being spread throughout the environment. We are trying to avoid some of these widespread things that happen when we dust, and the pesticide goes over quite a bit more than the original target area.

We recognize many of these things and we are attacking these things on a very broad front

MS. HOBSON: Do you have a follow-up question?

MS. FRENCH: He did not relate it to energy use. DR. YECK: Thank you.

The program has for the most part not been related to energy use. We are now beginning to look at that, but we have really been addressing the other issues, the environmental issues, more than the energy use at the present time.

I think Earle wants to take over a little bit on this.

MS. HOBSON: Does EPA: address energy use in the integrated pest management program?

MR. GAVETT: I am not aware that they do.

Chemical pestlcides use about 5 percent of the direct energy that is used in farming and it is an important part. I subscribe wholly to the integrated pest management philosophy and I believe most farmers do, too. But with only 5 percent of the energy used for pesticides, it Is really an insurance factor for the other 95 percent of the energy that is used to assure that there will be an output, and it is one of the most productive uses of energy that is used in the food system. 
MS. HOBSON: Jean, I think you have a comment.

DR. MAYER: I would comment on the last point and point out that indeed if we look at the world at large, the amount of crops which are destroyed after being. produced, before they are consumed, may amount to something like 30 percent of the whole food b111 produced in the world. The quickest way to make more food available to the world is to cut down on pests which destroy the crops after they are produced.

At the same time, I think there is a very good example there of the trade-off I was speaking about between capital and labor with resultant energy savings.

In those areas where the farmers are poor, mostly outside of the United States, a great deal of hand application on a very local point is used, say, to grow corn as compared to the area spreading that we do in the United States that requires a lot more manpower.

It has the same effect in terms of preserving the crops and it is certainly a saving of energy and a decrease in the threat to the ecology at large.

So we have a trade-off there that certainly is very important particularly in areas where technology is practiced.

MS. HOBSON: Thank you.

We have five more questioners, and I want to reach all ' In the remaining time. Those who may have had a question, please come up while we were talking and turn the questions in to us on the cards. We w111 make sure they are answered as part of the transcript. 
We will move to Merrill Whiteman.

MR. WHITEMAN: I am with Americans for Energy Independence, and this is following through on $\mathrm{Dr}$. Mayer's mention of the 16,000 1tems in the supermarket.

A modern, 20,000-square foot supermarket is lighted by 575 ceiling lights and 250 40-watt lights in the display cases. This translates into a 4,565-dollar annual light b111.

Giant Food Stores, Inc. says that refrigeration accounts for 50 percent of the stores' energy use and air conditioning and heat less than 15 percent. So, if lighting accounts for the remainder of the total, the electric bill is around $\$ 13,000$ a year. What is being done to reduce the wasteful use of energy assoclated with open refrigerator display cases, runaway increases in brand selection, excessive lighting, and proliferation of the so-called convenience foods?

MS. HOBSON: All right, are we dolng anything with grocery

stores?

\section{DR. CHIOGIOJI: Yes.}

Let me try to answer some of those questions. We are looking at the ways in which you can enhance the overall efficiency of grocery stores.

As a matter of fact, we are working on a project right now with Honeywell to try to determine, on a simulation basis, what kind of techniques can be used.

In the past, we have worked with the people in the supermarket industry to see what can be done to enhance energy efficiency within supermarkets. There are several studies done with regard to lighting and we believe that the lighting can, in fact, be reduced. However, what has happened in several instances is that where lighting levels 
have been changed, it has had a deleterious effect with regard to sales, so you have got a problem here with regard to the marketing aspects. One of the other things that we are looking at is with regard to heating of the supermarkets. In the wintertime lighting does add to the heating for the supermarket. On the other hand, in the summertime, it reverses the effect. We do have standards, or I should say guidelines, that can be used for lighting within varlous areas in supermarkets. I belleve that we have recommended 50 foot-candles. DR. BARTON: Just to note a possible alternative to supermarket retailing of food products which might produce energy savings: Congress passed the 1976 Direct Farmer-to-Consumer Marketing Act. The Department of Agriculture is now implementing that Act, which provides technical assistance and other kinds of assistance to everything from roadside stands, to facilities in downtown areas, to directly marketed produce, particularly fresh frutts and vegetables, from producer to consumers.

This is not going to have a global impact, but we may be able to market 1 percent of 2 percent of the food through this type of mechanism. This might provide better quality produce, and at the same time save some energy, because you don't need as much energy-expensive lighting and refrigeration.

One should not overemphasize what can be done in this regard, but it is something that can have some impact. 
Under the Farmer-to-Consumer Direct Marketing Act of 1976, the Department financed direct marketing activities in elght States in Fiscal Year 1977 and 17 States, plus Puerto. Rico in FY 1978. The program is designed to shorten the marketing chain between producer and consumer, thus reducing the amount of energy required to provide the consumer with a given amount of food, compared to what would be required in normal marketing channels.

Any reduction in the number of steps in the marketing system is a direct reduction of energy requirements, i.e., selling directly usually reduces or removes the cost of sorting, washing, grading, packaging, and transporting. Examples of projects with potential energy. gains are: development of backhauls for trucks carrying Kansas produce to other parts of the State; development of pick-your-own operations in several States close-in to urban populations; and development of fresh vegetable production near cities, for inner-city sale in Alabama, South Carolina, and Georgia.

DR. MAYER: Speaking of which, agian, we need to take a new look at that particularly wasteful phase of the whole system, where someone takes a two-ton automobile to go for so many miles to get 25 pounds of groceries. There are studies being made now, at least in supermarkets in the urban areas, in terms of shopping by phone and having a system of delivery trucks, which is a much more economical way of dealing with the transportation problems. Also it is a better way 
because it decreases the number of parking lots, which are both unsightly and often dangerous in citles.

This is an area in which we need to do more practical research because this is potentially a considerable source of energy savings.

MS. HOBSON: Thank you.

Dr. Michele Penick?

DR. PENICK: My name is Michele Penick, and I am with Positive Futures, which is the management arm of a consortium of higher educational institutions.

I am directing my quesition to that area. I would like to know what suggestions can be offered to higher education institutions as to the thrust that they should adopt in training individuals to be food and energy practitioners and also to be general consumers?

DR. MAYER: I am not really sure I really understand what is the scope of the question. I think that, inasmuch as problems shift from year to year and emphasis shifts of necessity, the answer would be that it is important that we continue to produce people who are welltrained in food and nutrition and also in what we are talking about today, as well as having a good, solid base in chemistry and physics. I think that every nutritionist and probably most technologists in the country would agree that one of the weaknesses in our system of education has been that nutritionists, though they know the effect of nutrients on the body, tend, by and large, to have very little knowledge of the processes whereby food is produced agriculturally. And, unfortunately, in far too many cases we have found that food technologies are concerned with only one piece of the system and are 
similarly ignorant and unconcerned with the nutritional consequences of what is being done.

So, my answer to the question would be that I would be in favor of a broadening of the education of people who are interested in food and nutrition to include a great many subjects, from chemistry to economics.

MR. HUGHES: It seems to me the question of how we motivate. people to act properly with respect to the energy-food relationship is simply one aspect of the general problem of motivating people to utilize energy, for whatever the purpose and whatever the source, more efficiently and, to conserve it.

Quite obviously, our success in achieving that in the Department of Energy is very limited. For better or worse, we don't know how to motivate people very well. When I say for better or worse, I think of my kids, who somehow did not do all those things that I thought they might do, and I suspect that some of your experiences are similar. The business of motivation, particularly when the direction of motivation is counter to the habits of a lifetime, is very difficult and, I think, this is another one of those questions to which the simple answer may not be accurate.

DR. CHIOGIOJI: You know we have been doing some work here and perhaps Mary Lynn Wrabel of my staff could glve you a little bit more information. 
MS. WRABEL: Yes, as Mel mentioned before, the Division of Education, Business and Labor has education programs for primary, secondary, and college-level programs.

This year they funded 68 faculty development programs at all levels. Two of them were in the food area and the only guidelines are that they have to be either a workshop or a seminar. A two or threeweek seminar is developed for either the faculty or the community within the area of a local university, but the university itself or the educational institution selects the subject that they want.

We don't specify the fact that it has to be an energy subject. So these programs are available and they have already funded the ones for 78 , but they come out each year with this faculty development program, so if you are interested, the best thing to do is contact this division:

MS. HOBSON: Which were the ones on food?

MS. WRABEL: The University of Iowa is conducting a program on home economics energy education and Cornell is doing a program on energy use and conservation, including nutrition systems.

Now, a final report will result from each of these projects, which I am sure you can get at the end of the year from this division. DR. MAYER: I think one of the major problems in this country is not so much the difficulty of motivating people as it is the fact that the message that people are getting is confused. I was concerned with the fact that, in our State in Massachusetts at the time when the 
crisis was evident, people were in fact extremely responsive. If you drove around the Massachusetts Turnpike, you would not have seen one car out of 30 that went over the speed limit and this was whether they saw a State policeman or not. People responded to what they saw as a national need.

Since that time, on the other hand, they have had the feeling that, first it was represented to them that the oil companies made enormous profits during that particular period. Secondly, they read about the oil glut in California and the fact that no one is quite sure of how to dispose of it. And pretty soon they were not sure that there is an energy crisis and, therefore, the problem is not so much one of motivation as one of understanding the problem.

Then, there is something else. There is a weakness, I think, in our overall educational system in terms of teaching people to come up with compromise solutions, which are usually the only solutions which are practicable. Because so many of us have been educated in this computer age, we are used to dealing with problems on a tiny piece-bypiece component, rather than as a whole, which would enable us to have a perspective on the relative importance of the pieces.

This is obviously essential to a certain extent because each process has to be made more efficient, but there are also the problems of general options and the integration of the system. There we are not only into intellectual problems, we run into ethical problems. 
We have taught our population, particularly our students, that there are certain things which ought to be avolded. We don't want to have black lung among our miners. We don't want to deface our lands through strip mining. We 'don't want to be dependent on the Arab chieftains for our energy supply. We don't want to expose our population to any sort of radioactive risk. We don't want to have large tankers come and pollute our coast. We don't want to have ofl platforms facing our beaches.

At the same time, we don't want electricity to be expensive, particularly for the poor. After you have set up all these propositions, each one of which is "a good thing," it becomes absolutely impossible to have any sort of energy policy and this is, in fact, where the public 1s; where the Congress of the United States is; and where, sometimes, the Administration is. And I think that, unless the problem is made very much clearer and unless there is some education in terms of where and how trade-offs are possible, we are not going to have a clear energy policy and, therefore, it is going to be very difficult to motivate our population to abide by something which, in their view; basically does not really exist.

MS. HOBSON: I think that is a very good statement. One of our office efforts is to try, however painful it is, to answer questions as they are asked. We try to give the consuming public information, so they can help us to make these trade-offs, rather than waiting for Washington to do it. 
So we appreciate that comment.

Wendy Galenter?

MS. GALENTER: I work with the Responsible Agriculture Project of the Action Center, and we are concerned with the percentage of research done at USDA and DOE, if any, on nonchemical means of pest control.

MS. HOBSON: Are you suggesting that this is an energy saving technique and, even though it does not perhaps save much energy overall, it certainly does to the farmer in terms of energy?

\section{MS. GALENTER: Right.}

It could be rough.

MR. GAVETT: The USDA non-chemical pest control program for FY 1978 totals $\$ 86,316,000$. The total pest control program w11l expend $\$ 127,267,000$. Thus, non-chemical control represents $68 \%$ of the total program budget.

MR. HARVEY: I can tell you that the Department of Energy is not expending any funds in this area.

MS. HOBSON: We will find out for you and put it in the record.

MS. GALENTER: I did have a follow-up.

MS. HOBSON: All right.

MS. GALENTER: I think the reason we are concerned is because we have seen throughout the years that industry, as well as Federal agencies, has spent a lot of time and a lot of money on developing chemical controls for pests, and that is one of the reasons for the great success of these methods. 
Relatively little has been done, mostly because it is not a profit-making venture, on nonchemical means of pest control and we are concerned with seeing that Federal agencles expand their efforts in this region.

I see it as a responsibility.

MS. HOBSON: Thank you.

We will find out what is being done.

Ne111 Richards?

MR. RICHARDS: I am with the United Church of Christ Action organization. The area of my question is in the food costs, but approached in a slightly different direction, so I will go ahead and read the question, although there have already been comments in the subject area.

The increase in residential energy costs impacts a fairly inflexible portion of a person's budget. That is, it must be paid or the supply is terminated. Thus, the cost must be absorbed by reduction of expenditures in other budgetary areas, frequently in the food area which has already risen in cost due in part to the increased energy costs.

What is DOE doing to help offset this impact, particularly on persons already in the grip of poverty? What resources and documentation on the extent and amelioration of this problem are available?

MS. HOBSON: Mel?

DR. CHIOGIOJI: Let me try to answer this.

There are a number of actions that are taken within the National Energy Act, which we hope will be passed within the next few weeks .

First of all, for the very poor, we do have a weatherization energy efficiency improvement program which is handled between the DOE 
and the Community Services Administration, and each of the 50 states have provided an overall plan of attack. We do work with the community action groups within each of the communities. In addition to this, the National Energy Act does have a tax credit program in which up to $\$ 400$ of tax credit would be provided for energy efficiency improvements.

We do have a major consumer information program, an information program on the various things that can be done to enhance energy efficiency. As a matter of fact, there are a number of publications that have been developed both by the DOE and by other agencies. For example, one happens to be done by HUD, called "In the Bank or Up the Chimey." We are also working on a homebuyers' guide at this point, in time, in conjunction with HUD, to try to achieve energy efficlency. As far as legislation is concerned, there is a provision to develop performance standards in Public Law 94-385 which is EPCA which says that by 1980 we will have energy efficiency standards for new bulldings. In old bulldings, we are working with ASHRAE to develop standards, called the 100-P series, which would help enhance energy efficlency within existing buildings.

Also, the efficiency program will help assist in increasing the energy efficlency of a home. Now, we do know that all these things are expensive and it does take money to be able to install all these things.

In other words, it takes money to save money, so that it becomes much more efficient from an energy point of view. That is the 
reason we do have these programs for tax credits to provide use for better return on investment.

So, I guess that covers it.

MR. RICHARDS: On that last point, about taking money to save money--and that, of course, is the problem when you are poor. How do they get involved 1n. this, because they are the ones getting hit with a crunch?

\section{DR. CHIOGIOJI: Well, we do have the' weatherization assistance} program in which the poor can get money to accomplish energy-efficient things like insulation, caulking, and those kinds of things. They can be working with their community action groups to get funding to do it on a grant basis. The program is run by Ms. Mary Bell within the Department of Energy, if you need any further information.

MS. HOBSON: There was no reference to food in your question, was there? . Just general?

MR. RICHARDS: Well, the problem is that energy costs like these have got to be paid. You have not got an option for it. Food is something you have control over, and that is where the energy money is coming out of. Food is a more flexible item. Energy cost has the impact of forcing you to buy less food, because your money is going to pay for that energy.

MS. HOBSON: I see.

DR. BARTON: The Department of Agriculture also operates a home insulation program of a similar type. It is operated through lending authorities of the Farmers Home Administration and at a local 
level through the local REA co-ops. We are finding that you have got to convince the people out there that they are going to experfence a real savings, a real payoff by putting in insulation, and that their energy costs are not going to go up commensurate with any savings that they would otherwise get out of home insulation before they are going to go into it. This may well be an area in which we can save money by spending money, helping to meet front-end costs with soft loans or dfrect assistance.

We could make these insulation programs more effective, and perhaps the economics would work out to everybody's benefit, if we added some additional front-end assistance.

MS. HOBSON: Thank you.

Mr. Ferdinand Hoefner?

MR. HOEFNER: My name is Ferdinand Hoefner, and $I$ am an interm with U.S. Food Policy. As has been pointed out today, several times, the energy cost of alternative methods of raising and feeding livestock ralsed a great many questions. The present USDA beef grading provides incentives to use more energy-intense methods at increased costs to farmers and to the nutritional detriment of the consumer.

I am wondering; will USDA respond favorably to legislative intiatives to reverse this built-1n energy inefficiency, or is $1 t$ planning to introduce its own standards in this regard?

DR. BARTON: The beef grading standards, as they operate . today, are a voluntary system. It is an industry financed system.

It is operated primarily as a commercial tool, and to expedite marketing, per se.

Assistant Secretary Carol Foreman has been working with the possibilities of adjusting those standards to make them reflect as 
accurately as possible nutritional factors. To the extent that you can do that, the grading standards could reflect back and adjust production to say, leaner beef. But I think if one wants to put the standardization program on the same basis, for example, as the meat and poultry Inspection program, you perhaps need to move to public financing in order to get a broader interest reflected in the program.

MS. HOBSON: Do you have a follow-up?

MR. HOEFNER: No.

MS. HOBSON: Before I turn the program over to Sam, I would like to say to the audience that we do appreciate your questions. I know the questions are always tough for us because, previously, we have not been answering in this organized form. We are learning to do that as we put our new agency together.

As you know, 25,000 brlefing summaries will go to consumer and public interest groups around the country. And we are also going to ask at this time for evaluations, so that we can get some ideas on how we can be more responsive to the individual and residential consumer, to get out accurate and substantive information, and to encourage the participation of all sectors of society.

So, we will be sending you some forms for suggestions, because we do want to take another look and see how best we can get the information out. Dr. Mayer also feels that this is essential.

Sam, you have got the last word.

MR. HUGHES: Thank you, Tina. 
As I indicated at the outset, this is our 6 th and final briefing for this fiscal year. I think there is little to add to what Tina has sald other than to thank our panel, both the DOE folks and the Department of Agriculture people, and to thank our resource people who have helped with the responses to a number of the questions.

Thank you in the audience for your patience and good questions, and most of all, thanks to our spectal guest and keynoter, Dr. Mayer, for his help with our session.

We will evaluate the reusits of these six briefings and see what we do about it then.

I expect we will be seeing some of you again in about another year, on perhaps somewhat different topics, or at least different aggregations of subjects.

Goodbye and Good luck.

[Whereupon at 12:00 $0^{\prime}$ clock noon the hearing was concluded.]. STATEMENT FOR THE RECORD

MR. RAY H. DALEY

OF THE

AMERICAN AUTOMOBILE ASSOCIATION

As a former member of the Consumer Affalrs Advisory Committee for both FEA and DOE, representing Triple $A$ and the consumer motorists Interests, my main focus was on transportation. But one cannot become deeply Involved in energy without becoming aware of the broader Impacts 
energy problems have on the consumers whether or not they operate an automobile.

For me, the greatest danger to the American consumer today grows out of the relationship of energy and food. The most productive worker in our nation and, perhaps, in the world is the independent American farmer. Because farm prices are so low that independent farmers cannot make enough to pay off the loans required every year to plant, nuture and harvest their crops, banks are cutting deeper into the farmers' only real capital...the land they own. Unlike the conglomerate agribusinesses that are moving into the business of supplying our food, independent farmers must accept the current market price. They have no massive reserves to allow them to withhold their grain or cattle from the market if the price is too low, and they must turn over their money every year. A conglomerate, on the other hand, may be willing to swallow the loss of a year's crop, presuming that sooner or later, because we must have food, we will have to pay the asking price.

The massive rise. in farm prices that the demise of the Independent farmer will mean to the consumer is not fust a reflection of the idea that all large corporate business is greedy and w11 soak consumers for whatever is possible. I don't believe that. But it only makes sense that a farm run with the superstructure of corporate management and manned by 8-hour-a-day, 40-hour-a-week untonized labor, cannot operate as economically as if 1 there run by the owner and his 
family, the independent farmer. As one publication on this topic so aptly puts it: "Who will sit up with the Corporate sow?"

I don't know the answe to that question, but I do know who will pay the overtime... the Amertcan consumer. And the rise in consumer food prices will be like nothing we have seen before.

Congress's answer seems to be to pay the farmers more for doing less so that the few acres they cultivate will bring higher. prices. Industrious farmers don't want to do that -- they want to work hard and prosper. That's why they are the embodiment of the American ethic.

No one seems to know what the President wants to do for the farmer, except that he doesn't want to do what Congress wants to. Indications are he has no answers for the farmer.

All too often federal agencies seem to adopt the attitude that because the nation's problems are so large tunnel vision is the only way to see ahead. The Agriculture Department doesn't want to become Involved in energy, and the Department of Energy doesn't want to solve farmer's problems. The farmer and the consumer, however, cannot conveniently isolate elther problem -- they do overlap.

Tina Hobson and her consumer office are to be commended for recognizing that and bucking the system. That kind of insight and courage are what makes $\mathrm{DOE}^{\prime}$ 's Consumer Department the best in government today. 
The price of energy is one of the big reasons the independent farmer is in such financial straits today. Another would seem to be that there tend to be surpluses of the crops that he produces. It would seem to make sense then to help the farmer produce a supplementary product that would a) cut down on the amount of energy he has to buy, and $b)$ be in limited or short supply and therefore readily marketable. By producing a supplementary crop that can be converted into energy (for which there should be a ready market), the farmer can take the pressure off the need for ever and ever higher prices for his food crops, including his cattle.

In other words, if we can help the farmer to this kind of solution, he can farm additional acres at a profit and, perhaps, he can still afford to sell us the food products at a price that we can afford. Good for the independent farmer and good for the consumer.

Naturally renewable things like farm crops, trees and wood waste, even organic garbage and urban waste, all can be made into alcohol, and alcohol is a clean-burning, efficlent fuel. Alcohol may be the answer for this problem of the farmer and the consumer.

On April 20, 1978, Jack Anderson's syndicated column carried a story about a black farmer in Alabama who is currently producing alcohol from excess grain and selling it to his farm cooperative members at 65t a gallon. The farmer's name is Albert Turner, and he doesn't interest DOE because his methods are rather crude and his output is small. 
The technology that Albert Turner uses may not be the best or most efficient, but it is appropriate for him, and it will help pay his bills.

A question I have been asked of ten is, "If alcohol is so good, why aren't we using it?" Perhaps Albert Turner's answer is as good as any. I met him in the summer of 1977, and the first words I heard Turner say were, "The government's looking for complicated (energy) answers that take a long time. Alcohol is too simple."

The objections to alcohol fuels no longer center on its feasibility, because there is too much evidence of how well it works in a blend with gasoline in our present cars. Even stralght alcohol works in cars or farm machines with some minor modifications. The objections are now primarily economic.

Speaking at Sen. Bayh's hearings, on Alternative Energy Sources, Dwight Miller of the Department of Agriculture's Peoria Research labs, a highly respected expert, provided a laundry list of things we could do to improve the economics and supply of energy from crops in the form of alcohol. Developing a varlety of new economical energy crops, improving the energy required for fermenting and distilling alcohols, and furthering work already underway in untversity laboratories on new and innovative ways to make alcohol from almost anything organic were some of his suggestions. 
(Government research in the areas Miller mentioned came to a screeching halt after World War II. The farmers and the consumers need that work to go full steam ahead.)

Despite this testimony from their own department, USDA produced a study that based all the information on corn, used 30-to-70 year-old technologies and priced everything as though farmers had to go out and start fresh to farm for energy. Results of this "scientific" study indicated gasahol would require a $\$ 10$ billion annual subsidy. Studies commisioned by the government and carried out by the Mitre Corporation and Stanford Research have a similar flaw -- they assume farmers have to start from scratch. That may be the acceptable way to do a theoretical study, but it just doesn't face facts. The facts are that the farmers have the land (millions of acres the government won't let them $f a r m)$, the farmers have the houses that they live in, the farmers have their tractors and their barns, their mowers and their baflers, and farming an additional 10, 20 or 30 percent is not going to cost as much as starting from scratch, in energy, time or money •

Then there are the surpluses and spollage. Some farmers have mountains of rotting grain they could neither sell nor store which now is not good for anything, except making alcohol. Alos, they produce each year substandard and diseased grains in varying quantities, much of it not fit for human or animal consumption, but fine for alcohol. 
Moreover, in rotation, certain energy crops would bulld up the nitrogen in the soil, reducing the use of costly, natural gas derivatives as nutrients.

Dairy farmers frequently have much more manure than they can use or sell as fertilizer. This, too, w1ll make great alcohol and still produce a marketable byproduct. And where milk is used to make cheese, the whey, which once had to be discarded (and caused pollution) can now be made into alcohol for energy. In fact, the cheese makers in Wisconsin are right now supplying much of the alcohol used in the gasahol being sold in Illinois.

Men and women with scientific knowledge and expertise are excited about the potential of alcohol fules as a naturally renewable energy source. And that excitement is not just recent. Henry Ford (the orlginal) and Alexander Graham Bell both said we would eventually turn to alcohol as a fuel. A growing number of our senators and congressmen are pressing for incorporation of alcohol fuels into our energy plans. Men like Percy, Bayh, Javits and Church.

The President and the federal agencles, however, continue to drag their feet, looking to ofl, nuclear and other macro solutions.: It is time for consumers to demand that independent farmers to be allowed to help solve our energy crisis, and at the same time save themselves from bankruptcy. 


\section{APPENDIX}

The following are the questions submitted by consumer and public interest groups prior to this briefing--and the answers to those questions as researched and prepared by appropriate Department of Energy program offices.

$\underline{\text { Question } 1}$

On May 20, 1976, the FEA Food Industry Advisory Committee (FIAC) under the Subcommittee leadership of Esther Peterson, now Special Assistant to the President for Consumer Affairs, voted on six consumer recommendations. The proposed studies were limited to identifying, organizing, and evaluating existing information in the following areas:

- Energy use and nutritional content;

- Energy conservation in food system packaging;

- Energy waste through food waste due to food system inefficiencies;

- Recycling, resource recovery, and waste reduction;

- Food system equipment efficiency labeling; and

- Energy efficiency guide for home food preparation.

Answer

The 1976 Food Industry Advisory Committee recommended to FEA that four of these six areas needed further investigation. At that time, the committee did not propose studies in:

- Energy use and nutritional content

- Energy conservation in food system packaging

The four suggested areas of research which the FIAC identified have been addressed and incorporated in the programs of the Divisions of Industrial Energy Conservation and Buildings and Community systems. Both of these Divisions are within the Office of Conservation and Solar Applications.

Energy Waste Through Food Waste Due to Food System Inefficiencies:

DOE, in its efforts to reduce the energy and food waste caused by food system inefficiency, has examined RD\&D ideas which have a positive energy impact. Recently, the Division of Industrial Energy Conservation analyzed the energy conservation potential of recapturing food waste which would subsequently be utilized for pet foods.

The Department of Energy is aware that the Department of Defense is planning to initiate a study on processing food waste into other useful products. 
Recycling, Resource Recovery, and Waste Reduction:

The Department of Energy's Office of Energy Technology has an extensive "Fuels from Biomass" program to investigate and demonstrate utilization of agricultural, forest, and animál residues to produce clean fuel products and petrochemicals.

In addition, DOE's Biomedical and Environmental Research Division is initiating a program in fundamental research on biological energy conversion and conservation. This program is aimed at performing the long term research necessary to underpin enhanced biomass productivity and the use of new innovative biological systems for conversion of wastes to fuels and chemicals.

The Department of Energy's Division of Buildings and Community Systems is conducting research on resource recovery and waste reduction from urban solid waste. Nutrients are recovered from these processes can be used for soil conditioning and as possible animal feedstock. The USDA is conducting research to recover the nutrients from farm waste which in turn is fed to animals. At present, there is a limited possibility to use the waste for human consumption. There are no accurate reports of how much food is wasted in restaurants or in the home.

\section{Food System Equipment Efficiency Labeling:}

The appliance labeling program being developed by the Federal Trade Commission will encourage manufacturers to produce and consumers to purchase, significantly more efficient appliances. As a part of this labeling program, manufacturers will be required to label each product with energy information to allow consumer comparisons. Energy improvement targets have been established by DOE for eight appliances and five more will be established in July. In addition, DOE is involved in developing a program to educate consumers with respect to the significance of annual operating costs and energy guides, the importance of energy conservation for the nation, the way in which comparative shopping could save energy for the nation and money for consumers, and other energy conserving matters.

Presently, the Senate Committee on Energy and Natural Resources is examining Section 16 of the proposed National Energy Act, which would require an 18 month study to determine the energy efficiency of 16 major equipment items such as boilers, kilns, furnaces, etc. At this time, DOE is awaiting legislative action. 
Energy Efficiency Guide for Home Food Preparation:

The Division of Buildings and Community Systems and the office of Education, Business and Labor Affairs is co-sponsoring the development of a two phase multi-media package (TV/literature, etc.). Phase I involved the development of the multi-media material package. Phase II involves the testing and evaluation of the material package. The University of Tennessee is the contractor and, is utilizing the technical agents from the Cooperative Extension Service (Tennessee) to communicate directly with the consumer.

Part of the program deals with home food preparation and an overview of the food chain. Once the testing and evaluation stage is completed, the material will be made available to state and local organizations interested in educating their constituents. (A final marketing plan for this package has not beeen completed as yet.)

The Office of Education, Business and Labor Affairs has published a guide titlted, "Energy Conservation in the Home." This curriculum guide was initially developed for home economics teachers. However, it is being used by a diverse group of users affected by residential energy systems. The document is available free from the Technical Information Center. Areas on food systems covered in the guide include: food purchase, food storage, food preparation, food cleanup activities.

DOE's Buildings and Community Systems program publishes a booklet, "Tips for Energy Savers." It is available free from DOE, Distribution, Washington, D. C. 20585. It provides low cost and no cost energy saving tips in the home, including practices in the kitchen. 
Question 2

In recent public policy debate on the expenditure of energy within our "food system," on-farm technologies seem to have received a disproportionate amount of attention. In the future, will other segments of our "food system" (manufacturing and processing, transportation, wholesaling and retailing, out-ofhome preparation, and particularly in-home buying, storage, preparation, and waste disposal) be receiving DOE attention more nearly in proportion to their actual energy expenditures and potential energy savings?

\section{Answer}

The federal role in the food system has been and is to assure a dependable supply of food and fiber for the United States and for export. The USDA has long been the federal partner of agriculture in meeting this challenge. This marriage of Federal and State sponsored production research and development with the agricultural community has made the U.S. the most productive nation on the earth.

Within the Department of Energy the Office of the Assistant Secretary for Conservation and Solar Applications (CSA) is organized to directly address the problems of increasing the efficiency of each of the energy end-use sectors, (transportation, residential, commerce, and industry) with major Divisions in Transportation, Buildings and Community systems, and Industry, as well as a Division of Solar Applications which covers several sectors.

The Division of Industrial Energy Conservation is directly concerned with improving energy efficiency of our industrial sector, including food production and processing. The objectives of this Division are to reduce the energy consumed per unit production throughout the industrial/agricultural area by:

1. Developing economically viable technologies to assist the industrial and agricultural sectors in reducing energy consumption by increasing the efficiency of operation

2. Accelerating industrial initiatives and promoting the acceptance of technologies in order to achieve meaningful energy savings

3. Establishing and maintaining national leadership in the conduct of analysis, design, experimentation and implementation of economically viable techniques for improving the efficiency of industrial/agricultural processes 
The Division of Industrial Energy Conservation/Agriculture and Food Process Efficiency Branch has actively sought and obtained the expert opinion of the food industry to provide counsel on its programs. The participants of the Division's workshops were representative of all phases of the U.S. agriculture and food industries from input chemicals to consumption. The results of these meetings have been extremely valuable in the formulation of RDAD programs in the food sector.

One of the earliest programs of the Agriculture and Food Process Efficiency Branch addressed the nitrogen fertilizer problem. Chemical fertilizer is by far the greatest energy input in production agriculture. The Division has demonstrated a process which saves $6.5 \%$ of the energy consumed in granular fertilizer production.

In fact, of the six most energy intensive crop production operations: fertilizer, irrigation, harvest, pre-plant, farm pick-up and crop drying, the Agriculture and Food Process Efficiency Branch has active programs in three. Harvesting techniques and pre-planting operations have been improved over the years under USDA leadership and work is continuing in these areas. Farm pick-up will benefit from ongoing DOE programs in the transportation area.

The food processing area includes a number of industries that are large users of energy. We have active or soon to be implemented programs in quite a few of them: meat packing, beet sugar, wet corn milling, canned fruits and vegetables, milk, cane sugar, frozen fruits and vegetables, and poultry processes. Other initiatives will be undertaken as our program matures. We welcome studied inputs in these as we do in all areas of the Division of Industrial Energy Conservation programs.

In the regard that on-the-farm production is getting a disproportionate share of DOE funds, the total FY 79 budget submitted to Congress for the Division of Industrial Energy Conservation is 49.4 million dollars. Of these funds. approximately $20 \%$ are proposed for the Food and Agricultural Branch of which approximately one third will be devoted to production agriculture and two thirds to food processing. This proportion is about the same as it has been since the. initiation of the program in 1976.

The expected energy reduction in the food production and processing area directly resulting from these activities are 0.12 quads in 1985 and 0.32 quads by the year 2000. 


\section{Question 3}

When will DOE be updating the Food Industry Advisory Committee initiated FEA report, Energy Use in the Food System? This useful publication compiled, organized, and evaluated existing energy data from agricultural production through food consumption--indicating that $16.5 \%$ of U.S. energy is used by the food system. Have any recommendations listed in that report. been explored?

\section{Answer}

The Department of Energy acknowledges the useful and comprehensive analysis which the Federal Energy Administration undertook in the report, Energy Use in the Food System. At the present, the Department of Energy, is not in the process of updating this document.

The conclusions of this report include:

- Improve coverage of capital and transportation energy use within the food system

- Determine post-embargo shifts in energy use due to price changes and conservation measures

- Establish appropriate energy and other economic benchmarks for energy use

In evaluating any project for funding, it is necessary to carefully determine the relative cost of the program and the benefit to be derived. The disaggregation of energy consumption data in the form recommended in the report would be an extremely difficult, time consuming, and costly project; while the data so obtained would only provide more accurate insight into the energy consumption problem. No improvement in energy use efficiency would result, thus DOE is not pursuing such a program. Modifications to these conclusions will be discussed with the Food Industry Advisory Committee, corporations required to report, and any other interested parties during the coming months.

Currently, data is supplied by corporations under the Energy Policy and Conservation Act guidelines. Major energy consuming firms in industry are required to report their total Btu expenditures by energy source, energy use patterns and energy efficiency. This voluntary and mandatory reporting system is currentiy being evaluated with the intent of improving the accuracy of the data at a reasonable cost. 


\section{Question 4}

Will DOE invest funds in the development of $\mathrm{K}-12$ curriculum materials on "Energy and Food" and in pre-service and in-service training of teachers on how to teach "Energy and Food" subjects?

\section{Answer}

The Education Program Division of the Department of Energy has developed energy curriculum materials appropriate for a variety of age levels in both primary and secondary educational institutions. Educational materials related to food and energy are available by contacting this Division. An example of a resource publication which would be suitable for the standard course of study. in the senior high school level is entitled, Acriculture, Energy and Society (grades 10-12). This interdisciplinary unit helps students to examine the nature of present-day agricultural methods and study the impact of these methods on existing energy resources. Community Workers and the Energy They Use (grade 2 ) reports on the energy consumed by such workers as farmers and grocers.

The Division of Education Programs has planned and organized effective methods of disseminating these materials so that educators can readily incorporate this subject as part of their teaching curriculum.

The Division sponsors a Federal Development Program which provides inservice training to teachers to prepare them to instruct students in different aspects of energy. This million dollar effort involves such activities as coordinating workshops through universities to instruct the educators. Cornell University was funded under the Federal Development Program to develop a project entitled "Energy Use and Conservation in Food and Nutritional Systems". The University of Iowa was supported in a "Home Economics Energy Education Project".

Other government agencies are involved in instructional materials and educational plans in energy. H.E.W. administers programs covering every level and aspect of education. Educational proposals in food and energy could be funded in such H.E.W. programs as community education, educational innovation and support, environmental education, teacher corps, etc. H.E.W. has funded 23 energy and food related programs between 1971-1976. Detailed information on H.E.W. projects and programs can be obtained from their Energy and Education Action Center. 


\section{Question 5}

Interest in urban gardening and greenhouse operations is mounting rapidly. Are these activities, if carried out correctly, more energy efficient than conventional production, transportation, packing and marketing systems? If so, what is DOE doing to encourage these practices and to aid in educating the public in correct gardening methods?

\section{Answer}

Whether or not these practices are more energy efficient or not depends on the equipment used, chemicals used and the preservation methods used. Only the small portion involving the substitution of labor would save fossil fuels. Larger scale operations are more efficient from a total production standpoint and commercial processing on a per unit basis would be more energy efficient than home processing.

Home gardening is more for hobby than energy or cost savings. studies have shown that most home gardens either barely break even or lose money in their operations. The inefficiencies of growing food on small plots would not make it feasible to depend on this methodology for major food production in the U.S.

However, USDA Extènsion Service sponsors various home gardening programs. In 1977, the USDA's Extension Service initiated a pilot program in urban gardening. In 1978, three million dollars was appropriated to fund sixteen extension service centers to assist urban residents in urban gardening techniques and greenhouse operations. In addition, USDA, through both the Agricultural Marketing Service and Extension Service, is involved in a program to improve the availability of fruits and vegetables to urban residents by producing and marketing the products locally. Information regarding these and other urban gardening programs techniques can be obtained by contacting state extension services. 


\section{Question 6}

Is work being done on the comparative energy inputs by various gardening techniques:

- home gardening with and without power tools;

- organic gardening with and without power tools:

- small commercial gardening with and without power tools;

- large commercial gardening with and without power tools?

Answer

No known studies have been undertaken on home gardening with or without power tools or organic gardening with or without power tools. Work by Steinhart \& Steinhart and by Pimentel have reported on comparisons of hand labor versus power equipment from several underdeveloped countries. Work by Heichel compared labor versus machine for corn production.

The Council for Agricultural Science and Technology pointed out in its report "Energy Use in Agriculture" (CAST Report \#68, August, 1977) the high cost of human labor versus power tools.

There is no doubt, for example, that farm work can be accomplished by expenditure of fewer calories of energy by people or horses than by modern farm machines and chemicals. The cost of the people and horses to do the work, however, is prohibitive in other respects.

In 1976, the average cost of employing a farm laborer in the United States to work a 10-hour day was $\$ 26.50$; but the physical work this laborer could perform could be purchased as electricity for only 3 cents. With this great difference in productivity of human energy and purchased energy, it is clear why machines are used to replace human labor in agriculture wherever feasible. 
Question 7

In looking to the full range of solar and renewable energy sources-solar heating and cooling, composting of animal and crop wastes, methane production, alcohol production and use, conservation measures, low-head hydro, wind power as well as combined systems - is DOE prepared to fund and coordinate an effort that would lead to increased energy self-sufficiency for the farm and the farm community?

\section{Answer}

The Department of Energy has five program areas that are addressing increased energy self-sufficiency on the farm.

*Agricultural and Industrial Process Solar Heat - This program has the objective of developing and demonstrating agricultural solar energy technology which can provide a substantial amount of process heat for (1) food processing, (2) grain drying, (3) crop drying, (4) livestock shelter heating, and (5) greenhouse heating. The USDA Agricultural Research Service is managing this program under the oversight of DOE. A description of these development and demonstration projects can be found in a program summary published in June, 1977 (Solar Eneray for Agriculture and Industrial process Heat, available from the Government Printing Office, Stock \# 060-000-00079-4).

*Industrial Energy Conservation - A program on Energy Integrated Farm Systems is being initiated by the Agriculture and Food Process Efficiency Branch of this Division. The objective of this program is to develop on-farm integrated livestockcrop-energy production systems that are economic, reliable, require minimum attention and maintenance, and minimizes the need for energy and material flow across the farm system boundry. A Program plan will be developed in late FY 78 .

*Wind Energy - One of the program elements of the Wind Energy Program is examining farm and rural use of wind energy systems. The objective of this program is to identify and test applications of small wind systems, assess the performance of available small wind turbines for these applications, identify small machine development needs, and develop and evaluate advanced small wind turbines.

*Fuels from Biomass - The overall objective of the Fuels from Biomass program is to develop the capability for converting biomass resources into clean fuels, petro-chemical substitutes, and other energy-intensive products that can supplement similar products made from conventional fossil fuels. The program is oriented toward growing terrestial and aquatic crops in energy farms rather than assisting energy self-sufficiency for food crop and livestock farmers. Information developed 
by this program should assist the Energy Integrated Farms System program in the Division of Industrial Energy Conservation.

*Biomedical and Environmental Research - This program has been attempting to initiate a subprogram in fundamental research on biological energy conversion and conservation. This program is aimed at performing the long term research necessary to underpin enhanced biomass productivity and the use of new, innovative biological systems for conversion of wastes to fuels and chemicals.

Coordination of programs will be accomplished through the secretary's office and through the DOE/USDA Memorandum of Understanding. 


\section{Question 8}

Is DOE planning to assist in the development of do-it-yourself technology for retrofitting solar energy systems to farms?

-Who is in charge of this work?.

-How will DOE assist in this development of technology-which groups are favored to receive grants and contracts?

\section{Answer}

The Department of Energy's program in Agricultural and Industrial Process Solar Heat has, in its development and demonstration program on agricultural solar energy systems, emphasized the development of systems that can be built, modified, repaired and replaced by materials which can commonly be found in a hardware store.

The Director of the Solar Heating and Cooling Applications program within DOE's Office of Conservation and Solar Applications is in charge of this work.

As stated in the response to question 7, development and demonstration of solar energy systems for the farm is being managed by USDA's Science \& Education Administration with the oversight of DOE. About 30-50 demonstrations of solar heating of livestock shelters on the operating farm will be funded beginning this year. USDA's extension service will be assisting in the choice of farm to be included in the demonstration so that a variety of climate regions and livestock farm types are included in the demonstration.

Three types of groups have been conducting development efforts over the past three years: government agencies (USDA and DOE laboratories), universities, and private firms and companies. 


\section{Question 9}

Approximately $75 \%$ of the anhydrous ammonia produced was consumed by the agricultural industry. Since some ammonia is found in the chemical reactions taking place in the coal gasification process, it seems reasonable to suggest that a process could be designed to optimize the direct production of ammonia. Does the Department of Energy R\&D effort on coal gasification include projects to develop methods for producing the anhydrous ammonia that is so vital to agriculture in the U.S. and developing nations? We also understand that nitrogen fertilizers can be made from alcohol and that leguminous plants and free living nitrogen-fixing bacteria can reduce the need for anhydrous ammonia. What is being done about this?

\section{Answer}

i) The total amount of nitrogen found in coal is in the range of 1-2\%. In the average case, about $75 \%$ of the nitrogen in coal will be converted to ammonia in the gasification process. Therefore, there is no real incentive to "optimize" the direct production of ammonia from the nitrogen in coal. The present United States demand for anhydrous ammonia is estimated at 17 million tons per year. At a conservative $3 \%$ per year growth in demand the projection for 1990 ammonia demand is 24 million tons per year. Some projections for coal gasification have estimated that from five to eight commercial coal gasification plants will be built by, 1990. The expected capacity of these plants is 200,000 tons of coal per day. Based on an average $1.5 \%$ nitrogen in coal and $75 \%$ conversion of this. to ammonia, there would be 2250 tons of ammonia produced per day, only about $3 \%$ of the 1990 demand.

The Department of Energy has included in its coal conversion program a demonstration plant for the production of hydrogen from coal gasification which W. R. Grace will use in the production of 1200 tons per day of ammonia. This program is aimed at producing an alternate source of hydrogen that is a direct substitute for the method of steam reforming of natural gas for hydrogen production which is presently used in most of the U.S. production of ammonia. This substitution of coal for natural gas will release the natural gas for other uses.

\section{ii) The Agriculture and Food Systems Branch of DOE is working} to encourage the development of new technologies that will accomplish a reduction in energy usage and dependence on premium fuels as inputs in the production of anhydrous ammonia. currently, the Branch has one project underway with, the Tennessee Valley Authority's National Fertilizer Center which is investigating processes for conserving energy in the production of fertilizers in ammoniation granulation plants. This four year project will develop new formulations which reduce moisture 
added in the granulation process and utilize chemical heatof-reaction generated by combinations of ammonia and phosphoric acid as a substitute for natural gas in drying granular fertilizer. It is estimated that fuel consumption in these plants can be cut by as. much as $6.5 \%$ using the new formulation procedure, resulting in a cumulative energy savings of 5.8 million barrels equivalent by 1985 with first savings occurring in 1979.

By August of 1978, the Branch will issue a Program Opportunity Notice on research, development, and demonstration of technologies which can improve energy efficiencies in the manufacture and use of nitrogen fertilizers. The areas to which the PON will be directed may include: 1) Programs directed to the development of alternate methods of producing hydrogen, 2) Energy conserving processes or process modifications in the production of ammonia, and 3) Reduction of fertilizer consumption via more efficient, use.

In the context of the use of leguminous plants which fix their own nitrogen, it should be pointed out that this is not a "something for nothing" activity. When a legume plant is involved in nitrogen fixation, it is at an energy cost and this is often reflected in reduced yields. Nevertheless, the dividends are probably worth the investment. Leguminous plants have the unique characteristic of fixing their own nitrogen through the use of a bacterial host. This allows the plant to convert the nitrogen into a soluble form which it can accept. The U.S. Department of Agriculture is conducting research on this matter, as are the state experiment stations affiliated with land grant colleges. DOE, however, has no mandate in this area, and due to the extensive work of the USDA, it is doubtful that an effort by DOE could speed the adoption of the results. 
Question 10

USDA projects indicate that the use of pesticides made from petro-chemical feedstocks will increase from 1.4 billion pounds in 1976 to over 2 billion pounds in 1987. Some believe that such projections can be cut in half and implementing recommendations to that effect have been submitted to EPA. Does DOE plan to review these recommendations and encourage the acceptance of those that have merit?

Answer

The Department of Energy currently has no knowledge of the specifics of any recommendations submitted to EPA. DOE is quite interested in reviewing all recommendations where signficant energy consumption is involved. The question of pesticides, though, is the responsibility of EPA under the Federal Insecticide, Fungicide, and Rodentcide Act. EPA has been undertaking a vigorous effort in reducing the use of pesticides via the integrated pest management (IPM) approach. EPA is working in cooperation with USDA in setting up IPM demonstrations in 20 states. Results have shown that yields can be maintained and pesticide use can be cut in half. Interested persons may wish to refer to the EPA Journal of March, 1978 (Available through EPA Office of Public Awareness). 


\section{Question 11}

What is DOE doing to encourage diversification of crops on the farm and to help agribusiness farmers, who are locked into energy intensive monocultures, move to more stable and energy efficient integrated farm operations?

\section{Answer.}

The Department of Energy is initiating a program on Energy Integrated Farm Systems within the office of Conservation and Solar Applications (a Notice of Program Interest will be issued in late FY 1978). The objective of this program is to demonstrate the feasibility of the energy integrated farm concept. The objectives of the program are the following:

- Development of on-farm integrated livestock-crop-energy production systems that are economic, reliable, require minimum attention and maintenance, and minimizes the need for energy and material flow across the farm system boundary

- Compare energy integrated farms with conventional farms. as to net energy saved, net profit, soil and water conservation effectiveness

- Determine potential of energy integrated farm systems for under-developed countries

The Department of Energy is not responsible, though, for encouraging farmers to diversify their crop. USDA has the responsibility to carry out these types of operations. 
Question 12

Is DOE willing to research and discuss energy requirements for growing various crops for animal feeds, including the use of:

- agricultural and manufactured by-products (e.g. citrus pulp), and

- brewery and distillery products?

\section{Answer}

The Department of Energy would certainly be willing to discuss the energy requirements of using the by-products of various food processing operations for animal feed. It should be noted, however, that agricultural and manufactured by-products, and the products of breweries and distilleries are currently in use for this purpose. The major amount of energy consumed in such processes is a result of drying the product.

The Department of Energy has several projects underway to minimize energy required for evaporation and drying. A manual for maximizing evaporation efficiency has been prepared

(Evaporation: A Prime Target for Industrial Eneray Conservation, COO/2870-1, Available from DOE Technical Information Center, PO Box 62, Oak Ridge, TN 37830). There are several programs that will be initiated soon in advanced concentration. Techniques such as Reverse Osmosis, Electrodialysis, and Ultra Filtration will be investigated as as an alternative to evaporation. 


\section{Question 13}

Rather than subsidizing farmers not to produce crops - couldn't we encourage these farmers to grow agricultural products healthy for the land and useful as a net energy source (biomass)? What is the annual cost to the American taxpayer of such current subsidies?

\section{Answer}

(i) The Department of Energy has investigated this area with particular regard to the use of alcohol as a fuel source. Ethanol and methanol are the alcohol fuels which are among the non-petroleum liquid fuel options that can be derived from resources available in abundance in the U.S. However, the most important barrier to the general acceptability of alcohols as fuels, is the fact that alcohol costs more than petroleum fuels. Methanol produced in large scale operations from non-petroleum resources may have a price comparable to current methanol manufactured from natural gas, but it would not be competitive with gasoline, at today's prices, on a dollars per Btu basis. In the case of ethanol, current and projected production prices based on fermentation of agricultural products are more than double those of methanol. On the other hand, ethanol from agricultural crops apparently has become cost competitive with industrial ethanol from petroleum.

Interest in alcohol production has also been sparked by some. non-energy issues. Because of present grain surpluses, local or regional proposals to use ethanol from grain as a supplement to gasoline have raised the issue of the need for government tax and/or other incentives to offset the high cost of production. Indeed, subsidization through tax credits and loan guarantees for new plant construction would allow for limited use of alcohol fuels on a local basis.

However, in the near term (by 1985), alcohol fuels are generally not likely to be extensively used on a commercial basis in the absence of federal initiatives because: (1) the production costs of alcohol are much higher than those of gasoline, (2) there is inefficient production capacity with which to supply such fuels, and (3) there is not ready end-use market and support infrastructure.

A factor that also has to be taken into consideration is mineral depletion of the soil as well as enhanced erosion. Research is underway both by USDA and DOE to evaluate the consequences of removal of biomass either as agricultural residues or as woody products. The virtues of allowing land to fallow should not be ignored. 
(ii) The direct subsidies provided to farmers under set-aside, disaster relief, conservation payments and other subsidy programs are estimated to be $\$ 3$ billion in FY 78 , and were $\$ .8$ bilition in FY 77 and $\$ .5$ billion in FY 76 . 


\section{Question 14}

What research is DOE doing now to compare the energy requirements of various food processing and preserving techniques:

-canning by home, community, and by industry:

-frozen goods;

-dried products; and

- fresh produce?

\section{Answer}

Research presently being conducted by DOE is examining energy conservation in processing foods, rather than comparing energy requirements of various processes. The National Food Processors Association is currently conducting an energy analysis and system study of three industrial complexes: a tomato processing plant, a spinach processing plant, and a peach operation. The Division of Industrial Energy Conservation is funding the study to assess the total potential for energy conservation in fruits and vegetable canning. A detailed accounting will be made of the energy used in the major unit operations employed in the processing of these commodities. Energy audits will be performed on common unit operations encountered in food processing to identify operations which are major users of energy. Model studies will then be conducted to determine the efficiency of each unit operation. This model will help suggest methods of conserving energy. An investigation will also be made of those operations which require large amounts of energy to determine methods of improving energy use and to examine process modifications of those operations.

The Agriculture and Food Process Efficiency Branch is supporting a study by the University of Maryland to assess the energy conserved and the characteristics of fresh foods preserved by GASPAK. This process could preserve solid food with perhaps one third as much energy as canning and about one half as much energy as freezing while maintaining nutritional value and attractiveness of fresh foods.

Several studies by the USDA have been undertaken to compare the energy requirements of various food processing and preserving techniques. "Energy Requirements in the U.S. Food System" examined the Btu output-input ratio required per dollar of canned fruits and vegetables and frozen fruits and vegetables from the agricultural production and transportation through the processing stage. The following are examples of some of the findings: 
canned fruits and vegetables

frozen fruits and vegetables

butter products and condensed-milk fluid milk
$45681 \mathrm{Btu} / \mathrm{s}$ of product

45735

37000

In 1976 the State of Washington funded a washington State University study on "The Impacts of Energy Price Changes on Food Costs". This study assessed the energy required per unit of final product from marketing through home preparation. The energy cost in dollars of all the energy in the system including home preparation was divided by the purchase price of the product.
canned peas
$3.2 \%$
frozen peas
$5.4 \%$
fresh potatoes
frozen french fries
$10.7 \%$
$5.9 \%$
dehydrated potatoes
$6.2 \%$

The energy cost per dollar in the processing stage is:
17 oz can of canned peas
10 oz frozen peas
$\$ .0034$
.0015
1 lb frozen frnch fries
.01
$1 \mathrm{lb}$ dehydrated potatoes .0358
$1 \mathrm{gal}$ fluid milk .0081
1 ib cheese
$: 0015$
1 Ib butter
1 ib dehydrated milk
.0067
.0138

Canned peas utilize more energy in the processing stage, yet it will utilize less in wholesale, retail, and in home preparation than frozen peas which must be refrigerated at each step beyond processing, thus utilizing more energy. The reasons canning requires so much energy in processing $(70 \%$ or more of the entire energy) are the large amounts of energy required to manufacture the can itself and the substantial units of energy required to sterilize the products in the can. 
Question 15

Has DOE initiated any studies comparing the nutritional content of food to the energy required by the various industrial processing techniques currently used by large manufacturers? What part of the energy used by manufacturers is used to process raw agricultural products (and chemicals) into "junk food" with little or no nutritional value?

\section{Answer}

The Agriculture and Food Process Efficiency Branch is supporting a Tufts University study in "Energy Use in Seafoods." This investigation will cxamine the energy requirement of seafood, not only in the processing stage, but will determine the energy used in harvesting, distribution, marketing and home preparation. Measurements will be made of the energy consumed in producing more highly processed, ready to cook seafoods. The nutritional output of all seafoods will be related to the energy input.

Additional material on this subject is availabe in a report by the USDA entitled, "Energy Value of Foods - Basis and Derivation."

Conflicting definitions of what "junk" food is, vary consumer preference and other higher priority areas of research dictate that DOE policy should be oriented toward more substantive areas of RD\&D in the Agriculture and Food Process Efficiency Branch. 
Question 16

Has DOE published a comprehensive and understandable economic and energy comparison of the use of returnable bottles, cans, and non-returnable bottles? What were the results? Such a study would be of interest to the public as well as state and local governments.

Answer

DOE has published a detailed study of beverage container deposit legislation. The study entitled, "Energy and Economic Impacts of Mandatory Deposits", was completed in september, 1976.

It can be obtained from:

\section{U.S. Department of Commerce \\ National Technical Information service (NTIS) \\ Springfield, VA 22161}

The full study is 750 pages and can be ordered in papercopy or microfiche. The order number is PB 258638-AS. An 18 page executive summary is also available: order number PB 258637-AS. Interest in the study continues to be widespread. In fact a draft of the study was distributed for review to other Federal agencies, industrial; environmental and labor groups and other knowledgeable individuals. Their comments and recommendations are included as an appendix in the full report. Another appendix shows the contractors' responses to these comments.

The study concludes that the results of a national beverage container deposit law will be determined by changes in consumer behavior, i.e. what types of containers they will purchase and how often they return those containers for recycling or reuse. Since there is no absolute certainty of any particular consumer response, the study examines many possible outcomes.

The study also identified a broad median range of consumer behavioral responses. Within this range, the study indicates the following results from a system with a depositable container: on the order of 70-81,000 equivalent barrels of oil per day would be saved; a net employment gain of approximately 117,000 jobs would occur, although 40-50,000 current jobs would be lost: an additional capital requirement of $\$ 800,000-2$ billion would be needed.

At the present time, the issue of Federal policy related to a national mandatory beverage container deposit law is being considered by the Interagency Resource Conservation Committee. This committee, established by Public Law 94-580 and composed of nine Federal agencies, will provide recommendations on various Federal policies -- including deposit legislation to the President and Congress. The final report of the committee is scheduled for late fall, 1978. 
Question 17

The use of energy intensive packing materials for food products has rapidly increased when compared to food production. The energy to manufacture packaging materials and apply them to food products represents approximately $10 \%$ of the total agricultural energy use or $30 \%$ of food processing energy use. Therefore:

- What kind of studies have been made to define food system packaging and overpackaging?

- Have any studies been initiated to define the comparative energy requirements of container styles and designs used in the food system li.e. corrugated boxes, wooden containers, folding containers, sanitary containers, paper sacks, steel and aluminum cans, collapsible tubes, aerosol cans, aluminum foil containers, plastic pre-formed containers, plastic blister and skin packaging, plastic packaging material, and glass bottles and jars)?

- What efforts have been made to encourage industry to use less energy intensive packaging materials?

\section{Answer}

a. Studies by the Federal government to define food packaging have been limited to food shipping containers. The General. Accounting office completed a study just recently entitled, Redesigning Shipping Containers to Reduce Food Costs. The conclusion of the report is that modularization of shipping containers can bring gains in productivity, reduce damage, and would assist in making better use of storage space on the wholesale and retail levels. For the food manufacturer there would be some benefits, but those would be outweighed by the cost of conversion. The USDA has also been working on standardization and improvement of design for produce and shipping containers.

b. No studies are underway. The Industrial Energy Conservation program held a workshop in March, 1978 on Energy Conservation in Food Distribution and Preparation. One of the four working groups dealt with packaging. A project suggestion, which was rated highly by the group, was a project to objectively evaluate the energy intensiveness of specific packaging products and materials.

c. There are no programs underway to encourage industry use of less energy intensive packaging. The Industrial Energy Conservation program is addressing packaging systems, but only with respect to those systems which can assist in conserving energy in the food sterilization process. 
Question 18

Should there not be a policy of consumer education on the comparative energy requirements of certain food containers - with advantages and disadvantages explained for various types (i.e. preserving quality, maintenance of nutritional content, disposal and other pollution problems, etc.)?

\section{Answer}

The Department of Energy feels that there are more important targets in energy conservation by the consumer than in disseminating information on comparative energy requirements of food containers.

The only efforts being directed toward packaging are by the Industrial Energy Conservation Program which is addressing packaging systems, but only with respect to those systems which can assist in conserving energy in the food sterilization. process.

In March, 1978 the Agriculture and Food Process Efficiency Branch of the Industrial Energy Conservation Program held a workshop on Energy Conservation in Food Distribution and Preparation. One of the four working groups dealt with packaging. Eleven project suggestions were submitted by the working group. A published proceedings of the workshop should be available by August at the DOE Technical Information Center, PO Box 62, Oak Ridge, TN 37830 . 


\section{Question 19}

Approximately $9 \%$ of the U.S. energy requirements related to food is used in transportation. A Federal Trade Commission ruling has the effect of forcing trucks that have hauled groceries from company warehouses to its stores to return to the warehouses empty. The FTC ruling economically prohibits these empty trucks from picking up goods from a supplier's warehouse enroute. Instead, other carriers haul these goods over the same routes followed by the empty trucks. A Federal Energy Administration estimate placed the potential fuel savings by eliminating deadheading at 100 million gallons of gasoline per year in the food industry alone. Is any action being taken to eliminate this situation?

\section{Answer}

The findings of potential fuel savings by eliminating deadheading were made by the Food Industry Advisory Committee. While FIAC contributed greatly to FEA's ability to understand the nature of the problem, FEA had reservations as to the Committee's estimates.

The Interstate Commerce Commission has the prime responsibility of enforcing the laws which regulate the trucking industry, and in intiating legislation aimed at reforming such laws. The Department of Energy, however, has cooperated with the ICC in promoting energy conservation matters in this area. Indeed, the Federal Energy Administration, and its successor the Department of Energy, have supported ICC initiatives aimed at increasing the energy efficiency of trucking operations. The FEA supported the Diesel Fuel and Gasoline Conservation Act of 1977, with reservations concerning the actual amount of fuel which would be saved. This law would have permitted backhaul allowances under the Robinson-Patman Act, and would have provided truckers the opportunity to reduce the amount of empty backhaul their vehicles run. Though fuel savings might have resulted, the congress failed to pass the Act. DOE currently supports the ICC's effort to encourage more tripleasing movements.

In short, the DOE is cooperating with a number of Federal agencies to achieve near-term energy conservation in the existing transportation systems in order to provide consumers., the business community, and public officials the information necessary to assure energy conserving vehicles, equipment purchasing, operating practices, and to reduce or eliminate regulatory and institutional barriers to energy conservation in the transportation sector. 


\section{Question 20}

On an energy use basis, it takes 2.7 times as much energy per ton mile to ship by truck as by rail. There were 98,000 railroad refrigerator cars in service at the end of 1976 carrying primarily fresh and frozen vegetables from processing plants to market centers. Most of these refrigerator cars are used by major western railroads to haul perishable foods from California. In the East, trucks have captured essentially all of the long haul refrigerated food business from the railroads. As a result, there were less refrigerator cars in service in the U.S. in 1976 than in 1975. What is being done to encourage use of the more energy efficient rail transportation in the hauling of perishable foods?

\section{Answer}

The Department of Energy and its predecessor, the Federal Energy Administration, have studied with the Interstate commerce Commission the feasibility of modifying specific operational characteristics of the railroads and the regulated motor carriers. These modifications would increase carrier operating and fuel efficiencies and where feasible, shift some of the freight traffic back to the less energy intensive railroads. The development of a coordinated truck-rail service provides the greatest potential for an energy efficient freight transportation system. Motor carriers have an economic advantage in handling short haul freight (under 300 miles); whereas railroads have the advantage. in long hauls (over $300 \mathrm{miles).} \mathrm{DOE} \mathrm{supports}$ a transportation system which combines the best of both modes.

In addition, the railroads must increase their service effectiveness in order to improve their competitive ability and attract a larger share of the freight traffic. Their line haul efficiency, rates of equipment utilization, and financial conditions must necessarily be improved. During the past decade motor carriers have been significantly increasing their share of the inter-city freight market, primarily because they have exhibited an advantage in their ability to operate more efficiently in certain market segments where energy intensiveness is offset by speed, reliability, and the delivery concept of particular commodities. If the railroads are to increase their competitiveness in the inter-city freight market a number of system changes are needed.

Although there are a number of constraints towards improving the energy efficiency of the inter-city transportation system, DOE in conjunction with the ICC is working to implement new policies that would allow for a less energy intensive transportation system. 
Question 21

What is DOE doing and what recommendations are being made in terms of our food transportation system? More specifically, why does the U.S. encourage long distance shipment of food and world-wide "global supermarket" at the expense of local food self-sufficiency?

\section{Answer}

The Department of Energy has been working with the Interstate Commerce Commission to implement policies thát will bring about a more energy efficient transportation system. One of the keys to achieving this is to increase the role of the railroads in the shipping of commodities. During the past decade, the more energy intensive motor carrier vehicles have increased their share of the inter-city freight market. DOE has encouraged the ICC to reform regulations which impede the development of intermodal transportation systems. It is felt that the development of a coordinated truck/rail service provides the greatest potential for an energy efficient transportation system. Some other objectives sought by DOE to improve transportation efficiency include: (1) the pooling of freight in remote areas where traffic is scarce, (2) revising the existing rate structure to create a more flexible regulatory framework for promoting more efficient use of modal capacity. increased productivity, and improved energy efficiency, (3) encouraging more trip-leasing movements, and (4) including performance specifications in the overall basis of general revenue, as maximization of productivity will reflect improvements in modal energy use.

As far as long distance shipment of food is concerned, the U.S. has not encouraged this practice; rather, it is a result of consumer demands in an open marketplace. Certain commodities cannot always be supported by climate conditions in areas of greatest consumer demand. While vegetable and citrus products can be grown in artificial environments (greenhouses), such ventures are highly energy intensive, requiring a greater expenditure of fuel than does shipping. Indeed, only through heavy-handed government intervention could local selfsufficieñcy take precedence over the free market system of supply and demand. This type of intervention could well. increase the overall costs of food to the consumer. 


\section{Question 22}

The FEA Food Industry Advisory Committee repeatedly asked FEA to investigate/initiate reforms related to ICC regulations which require trucks to make repeated empty trips--wasting a significant amount of energy and adding to the consumer cost of food. FEA did nothing. Will DOE address backhaul and. intercorporate hauling issues-focusing on energy waste and the added costs to consumers?

\section{Answer}

The FEA, and presently the DOE, have encouraged the ICC to implement changes in industry regulations that would allow for a more energy efficient motor carrier transportation system. One of the key changes that all of the agencies have worked for, is a reform of the Robinson-Patman Act which limits backhaul allowances for private truckers. The Diesel Fuel and Gasoline Conservation Act aimed to remedy this and would have reduced the amount of empty backhauls vehicles run. However, despite FEA and ICC support of the bill and despite the potential energy savings, the legislation failed to pass congress.

While DOE and ICC will continue to cooperate on backhauling regulations, their cooperation has also extended into other areas. The Department of Energy is encouraging the ICC to cetermine ways to make common carrier carriage more attractive to shippers, as it is less energy intensive than is shipping by a private motor carrier. The Department of Energy is also pushing for legislation that would re-introduce joint rates and through rates for combined rail/truck shipping. This provides the greatest potential for an energy efficient transportation system. In addition, the two agencies are working to increase the service effectiveness of the railroads, in order to improve their competitive ability and attract a larger share of the freight traffic to this less energy intensive transportation mode. Thus, DOE and ICC are coordinating their efforts in an array of areas to redice energy waste in the transportation of commodities. 


\section{Question 23}

There is a growing trend towards consumer involvement in alternative food distribution systems such as farmer's markets and food consumer cooperatives. Such institutions typically reduce the number of middle people between the farmer and consumer. Because consumer cooperatives often buy foods in bulk, a large potential exists to decrease the energy used for packaging and processing. In one cooperative studied where consumers phone in orders which are delivered by truck, transportation to and from the store can be decreased. What is DOE doing to evaluate these practices and to encourage those that are sound from an energy and economic point of view?

\section{Answer}

The legislative authority for alternative food distribution systems principally resides with USDA as a result of the Farmer to Consumer Direct Marketing Act. The funding for this program has increased from 0.5 million dollars for FY 177 to 1.5 million dollar for FY 178. Requests for extensions, now before Congress, would increase the funds available to $3.0 \mathrm{milli}$ on dollars for FY 179. Thus, if the extensions are approved the program will have grown six-fold in three years. Since the legislation for this program was initiated by both Houses of Congress, prospects for continuing a program that has received considerable public support would seem excellent.

The 23 projects funded in 24 states and Puerto Rico range from pick-your-own farms where the buyer supplies the harvesting labor to farmer operated road stands to inner city vegetable market and grower operated individual delivery systems. where the farmer distributes his own produce. Although funded and reviewed by USDA, these projects are administered by state departments of agriculture through their extension services.

Clearly, there are energy savings to be found in these laborintensive projects, but the true advantages would seem to cover a broader range 'of socioeconomic issues. For the small marginal farmer, it offers a means to continue his vocation which he might otherwise be compelled to abandon. Picking your own vegetables or patronizing a roadside stand not only eliminates the cost of the middleman but also provides the urban consumer a recreational diversion as well. The urban farmers's market, consumer cooperative or independent farmer vending his own produce provides an invaluable service in the inner city with poor and aging populations or those limited by inadequate public transit and lacking private means of transportation. These experimental alternative distribution systems are not limited to vegetable produce: some are livestock operations where the emphasis is on gaining information for pricing and buying 


\section{6}

decisions to be made on the whole animal when purchased by the consumer before slaughter as well as changing the traditional relationship between the raiser and processor as far as ownership of the animal before and after processing is concerned. 
Question 24

Is consideration being given to the fact that hundreds of thousands of meals are being delivered daily by retired volunteers to home bound elderly and handicapped persons? What can DOE do to help ensure the continued availability of this vital service in the face of rising gasoline prices?

Answer

The legislative authority in this area resides almost entirely in the Department of Health, Education and Welfare and its Administration on Aging ( $A O A$ ). Title VII of the Nutrition Act funds programs that provide meals to the elderly by supporting organizations that operate those programs, but the majority of the money is spent on meals provided at central locations. Approximately fifteen percent of these funds are being put into programs for the homebound elderly, but that decision is made by the state or local, organization that is operating the program. The same is true of Title XX of the Social Service Act which requires that states develop their own plans. There are both mandatory and optional requirements for such plans so state and local plans can differ widely. Transportation programs for the elderly and "meals on wheels" type programs can be funded under Title XX which requires matching funds, but those two type programs are not mandatory, at the state and local level.

As a result of the gasoline crisis of 1974 , the AOA made recommendations to the various state agencies that they solicit resources from the older Americans Act to help meet the burden of increased transportation costs. This suggestion was not a mandatory requirement and few states took any action, and little, if nothing, has been done since. In general, although no mileage reimbursement for volunteers has been established as requirement for the state-administered programs, the increased cost of gasoline has not had a seriously deleterious effect on home delivery programs. This is primarily due to the increased appropriations for these programs and their ability to absorb these costs with administrative overhead. Basically, AOA feels that it is an issue that should be addressed by DHEW and not DOE since it directly involves the delivery of social services.

The House Select Committee on Aging has recently approved legislation that for the first time would create a separate national program for home-delivered meals for the homebound. This program (eighty million dollars for FY 79), administered by the AOA, would not require a means test for the participant but would require a contribution from each participant for the delivered meal. The contribution could be any amount, however small, that the participant wished to pay. Volunteers 
working in the programs would be reimbursed for the expenses. The bill also provides for a study of the cost of delivery of meals in rural areas where the cost of gasoline is especially worrisome because of the distances involved.

The question of the rising cost of gasoline-is actually somewhat ambiguous because of inflation. The real cost of gasoline has actually declined somewhat since 1976-77. Future projections show the cost of gasoline rising in conjunction with inflation. Only an increase in the world price of petroleum by OPEC should change that picture. However, in case the OPEC countries should agree to a major increase in prices or take even more drastic action such as another embargo, a contingency plan to counter such action is being prepared by DOE. Although the current draft plan does not specifically respond to the question of gasoline rationing and its effects on voluntary social service activities that rely on transportation, the issue has been raised by DHEW and others and is recognized as deserving further investigation. DOE recognizes this issue as a valid concern. 


\section{Question 25}

Recognizing the public health, environmental and energy consequences of eating habits, could DOE provide the public with a chart that would explain the energy, economic, and environmental costs of various types of food in terms of: nutritional values? Comparison of foods such as feedlot beef, range-fed beef, sheep and goats, chicken, eggs, milk and dairy products, fish, breads and cereals, vegetables, fruits and nuts, etc., would be very helpful.

\section{Answer}

There is no comprehensive chart which relates economic, energy, and environmental costs to nutritional values. To undertake such a task would be monumental and highly complex. Also any such chart would never produce a modicum of agreement within the scientific community.

However, studies are available which analyze each individual aspect or relates nutritional factors to energy. For example, DOE's seafood study compares the energy input to the nutritional value of the seafood. USDA's study on the energy requirements in the food system examined the Btu output-input ratio required' per dollar for canned and frozen products from the agricultural production and transportation through the processing stage. The Human Nutrition \& Family Living Center of the USDA published a table of nutritive values for a variety of foods from their. raw state to the processed state (on as purchased basis). 


\section{Question 26}

We use 450 billion cubic feet of natural gas annually to produce the $12 \mathrm{million}$ tons of anhydrous ammonia used for fertilizer. The 240\% increase in U.S. corn yield between 1946 and 1970 involved a $310 \%$ increase in energy used to produce the corn. Since most of the domestic corn production is used for livestock feed, it follows that important savings in natural gas consumption can be achieved by a change in our eating habits away from meat and poultry products to cereal-grains, legumes and nuts as the source of protein. What is the Department of Energy doing to encourage a shift in eating habits toward consumption of highly nutritious but less energy intensive foods?

\section{Answer}

High yields in agriculture, which is of crucial importance to the U.S. and the rest of the world, demands energy inputs. Developing countries have persistent food deficiencies because they lack the energy inputs necessary to enhance food production, particularly with respect to fertilizer and irrigation.

In this country, farmers cannot economically afford lower yields. They must use fertilizer if they are growing corn or forage, etc., regardless of whether these products are fed directly to humans or to animals. If there was a significant shift in the consumption of animal products, it would make little difference with respect to the utilization of fertilizer for cropping. Farmers want to be just as cost effective as anyone else and the use of fertilizer, within limits, is definitely cost effective.

It should be noted that those food products which are better nutritionally (rich in proteins and high in unsaturated oil) take more energy to produce within the plant; that is, high quality legumes more often yield less than low nutritional quality materials such as sugar cane and maize....... This is a general relationship which is currently beginning to become understood and should not be confused with the external inputs of energy that the farmer adds in growing the crop.

The Department of Energy has the responsibility to develop and commercialize technologies and systems which will contribute to the national energy program. The Department of Energy is not responsible for shifting and/or directing consumer preferences from one food product to another.

Department of Energy programs are, as described in question one, oriented toward more energy efficient residential practices and energy conservative heating and refrigeration systems. 


\section{Question 27}

Could DOE and USDA cooperate in comparing the energy. nutritional and economic factors of various forms of shopping, refrigeration, packaging and preparation of food?. For example, in terms of nutritional value per pound of food consumed, it would be interesting to compare the energy and economic cost of imported frozen beef with locally grown vegetables or chicken that can be purchased at a market within walking distance and prepared before refrigeration.

\section{Answer}

USDA and DOE under a Memorandum of Understanding have proposed the establishment of working committees in an effort to identify and conduct joint activities on energy. Areas of coverage will include:

1. Electrification in the Agricultural Sector

2. Energy Conservation in Agriculture

3. Solar Applications to Agriculture, Forestry and Rural America

4. Extension and Outreach Programs

5. Biomass as a Source of Energy

6. Finance and Incentives

7. Inventory of Agricultural Energy R\&D Projects

8. 'Special Ad Hoc Study Groups on Electric and Hybrid Agriculture and Personal-Use Rural Vehicles

There are no plans by either agency to undertake such a project under the Memorandum of Understanding. As described in Question 25, there are several individual studies that have been undertaken by both USDA and DOE which examine nutritional, energy and economic factors of individual foods, but no comprehensive survey has been undertaken by either Department. 
Question 28

What do we know about the varying efficiencies of gas, electronic, and microwave energy sources? of stove top versus oven cooking methods? How has this been studied and what problems has it encountered? Can we rank varying factors which effect cooking efficiencies (i.e. chef's habits, portion size, level of processing, energy source, food preparation method, etc.)?

\section{Answer}

Energy efficiency in cooking varies considerably with the type of appliance. The cooking efficiency at point of use in a home is approximately 75 percent for an electric cooking top (stove top), 45 percent for a gas cooking top, 13 percent for an electric oven, 8 percent for a gas oven, and 42 percent for a microwave oven. For the majority of consumer cooking applications, cooking tops have higher efficiencies than do ovens. Preparation of a typical weekly menu for a family of four is indirectly used as a basis in laboratory test comparisons of cooking efficiencies of kitchen ranges and ovens using a DOE test procedure published in the Federal Register. in May 1978.

Cooking efficiency varies for reasons such as the following: choice of cooking appliance inçluding its built-in enegineering design characteristics, type and quantity of food being prepared, and degree to which the cook takes advantage of energy conservation tips (such as not opening the oven door unnecessarily). Limited information is availabie which rank the factors which affect cooking efficiencies. For example, preheating can reduce the cooking efficiency of an electric oven by 1 percent to 3 percent; baking several items separately is done at a much lower overall cooking efficiency than if the items are cooked together, and the most suitable appliance to use often depends upon the type and quantity of food to be cooked. There are a number of sources of energy saving techniques such as the DOE Tips for Energy Savers. 
Question 29

Every time we eat in restaurants I am shocked at. the food waste which I view also as a significant energy waste. Has any research been done in this area or is any effort being made by DOE to encourage restaurants, cafeterias and coffee shops to decrease food waste through such means as serving portions more suitable to the consumer ( $i . e$. small, medium, large)? This single tcchnique would appear to not only save energy (in the production, distribution and disposal of wasted food) but also consumer dollars.

\section{Answer}

According to a recent survey by the National Restaurant Association, the majority of consumers do not believe that the portions served in restaurants should be curtailed. DOE has not studied this question.

What DOE is doing, which is in line with the agency's mission, is to look at the restaurant industry as one of a variety of "types" of energy users. DOE's Division of Buildings and Community systems is sponsoring a demonstration of energy conservation in restaurants. The project is being conducted at a. Jolly Tiger restaurant in Colonie, New York. The restaurant's heating, ventilating, air-conditioning and food furishing operations have been designed to include a complete system of energy conservation and reclamation equipment. A set of monitoring instruments will provide data on energy use in the restaurant.

The Department of Energy also has a publication entitled Guide to Energy Conservation for Food Service which is available through the Superintendent of Documents, U.S. Government Printing office, Washington, D.C. 20402 (GPO stock \# 041-018$00085-2)$. 
Question 30

The Department of Agriculture has a cosmetic grading system for fresh fruits and vegetables and other products which results in significant food (and energy) waste. Has DOE encouraged USDA to evaluate and change this system in light of today's energy priorities?

\section{Answer}

The Department of Energy has not encouraged USDA to change its cosmetic grading system. This grading system is designed to protect the consumer. The "waste" referred to is not actually disposed of, rather it is sold as culls or feedstock. The Department of Agriculture has its own energy office and has always carried a strong interest in energy conservation. The two departments, however, have agreed to work towards other common objectives. Through the proposed Memorandum of Understanding, the USDA and the Department of Energy have agreed to formulate and execute programs aimed at: reducing energy consumption in the food, fiber, and forestry sectors, encouraging efficient use of energy in rural living, substituting renewable or non-renewable sources of energy for scarce forms of energy, and assuring adequate energy supplies for agricultural and rural America. Specifically, the two Departments will cooperate in the planning, funding, direction, and conduct of a National Agriculture Energy Program to take into account USDA and Department of Energy priorities and objectives. 


\section{Question 31}

As we increase our demands for food and begin to use the biomass as a source of renewable energy, we will further stress the productive capacity of our land. Under these conditions, it is imperative that we rapidly move to land disposal of our energy laden municipal wastes. What is DOE doing to encourage EPA to rely more heavily on pretreatment of waste at the source before they are released into a public system? What is DOE doing to encourage EPA to further emphasize land disposal of composted. waste as the preferred method of dealing with municipal waste?

\section{Answer}

The Fuels from Biomass Program is working to study biomass resources, estimate production costs, and identify and evaluate conversion processes. Indeed, the program offers a significant potential for reducing the country's dependence on fossil fuels through the conversion of a renewable energy source to useful liquid and gaseous fuels, electric energy and petrochemical substitutes. The Fuels from Biomass Program gives special attention to the following environmental issues:

- The potential for erosion and depletion of soil organic if too many residues are removed

- Secondary impacts associated with large scale farming and conversion operations

- Particular emissions from direct combustion

- Disposal of residuals from conversion processes

However, the potential environmental impacts of biomass based energy production are small compared with the use of most other energy forms.

In any case, the use of municipal waste as a soil amendment can be useful in certain areas. However, in most major industrial areas sewage sludge contains metal toxins and hydrocarbons which hamper utilization of wastes for fertilization purposes. Indeed, sewage sludge may be better utilized in the production of methane gas. Currently, the Department of Energy is sponsoring a project in Pompano Beach, Florida aimed at establishing information on the quality and quantity of gas produced via anaerobic digestion.

In addition, the Department of Energy has a Memorandum of Understanding with EPA with specific emphasis on recovery of energy materials from waste. With regard to pretreatment of sewage wastes, EPA already has an active program in this area, 
and the Department of Energy is not encouraging EPA to intensify its efforts. The Department of Energy's interest is focused on direct energy recovery from wastes which are currently landfilled within the local economic limits in any specific area. The Department is working to achieve commercialization of the biological or anaerobic digestion systems which provide methane gas. 


\section{Question 32}

Throughout the food system, from the farm to the table, there is a great deal of waste. Too frequently these valuable nutrients end up in the sewers and become contaminated by other wastes. What is DOE doing to evaluate the potential energy savings along this line and to encourage practices that will either prevent such waste or recover the nutrients for other purposes?

\section{Answer}

The Department of Energy has been conducting studies on urban solid waste utilization for energy and material resources. The mineral portion of urban solid waste is a productive source for energy. The solid waste originates from urban, agricultural, forestry and industrial environments. Three broad technologies are used to develop waste utilization systems:

- Mechanical or separation systems - producing refuse derived fuels or organic fractions and materials, through magnetic separation, aluminum magnetic separation, jigging or froth flotation for glass

- Thermal systems producing organic liquids

- Biological systems - produces compost, an excellent soil conditioner, through aerobic digestion; algae can be grown on sewage sludge as another biological process to produce gas, or processed to recover combustible organic liquids or dry fuels

In order to stimulate the recovery of energy and materials from wastes, DOE plans in the future to match the quantity. and quality of the urban waste stream to the available system.

There are no accurate reports of how much food is wasted in the home. DOE is not conducting activities in this area. The USDA, though, is conducting research to recover the nutrients from farm waste which in turn are fed to animals. At the present, there is a limited possibility to put it back into a form suitable for human consumption.

For the last several years, the Whey Products Institute has been conducting research on recovering the whey lost from cheese and converting it back into a form suitable for human consumption. The USDA is co-sponsoring this program by providing about one million dollars each year. This process is standard practice since the EPA prevented the dumping of whey several years ago. 


\section{Question 33}

In the production of food in an energy efficient manner, water in many parts of the country is becoming critically important. As the water table drops, more and more energy is required to pump the water needed to support agriculture. What is DOE doing, in cooperation with other departments and agencies, to encourage water conservation in those sections of the country impacted by this situation?

\section{Answer}

One of the top priorities within the Agriculture and Food Process Efficiency Branch of the Department of Energy, is the encouragement and participation in the development of new or improved technologies that will yield greater efficiencies in irrigation pumping plants, irrigation system designs, and improved water management while maintaining high levels of productivity. of particular interest to the Branch are:

1. Irrigation pumps that are more efficient than conventional pumps (under conditions experienced in the field)

2. Irrigation wells that have minimum drawdown (differenoe between static water level and the dynamic pumping water level) head at rated pumping capacity

3. Sprinkler systems that operate effectively at pressures significantly lower than conventional systems

4. Irrigation water distribution systems that reduce irrigation pumping energy requirements by improving water application efficiency (less water pumped as a. result of more uniform application and/or reduced evaporation and percolation losses)

5. Methods for significantly improving irrigation prime mover efficiency, and

6. Energy efficient irrigation systems using systems design and optimization techniques

The Department of Energy is currently sponsoring ten projects throughout the country, aimed at meeting the above objectives. The U.S. Department of Agriculture is also undertaking research aimed at energy conservation through more efficient irrigation techniques. 


\section{Question 34}

Given the developing energy and food shortages throughout the world, should the U.S. become increasingly dependent on imported food from developing countries? What role does DOE play in the transfer of agricultural technology to developing countries to cnsure that the technology is appropriate in terms of projected energy availability?

\section{Answer}

i) The developing energy and food shortages throughout the world will have the net effect of increasing foreign dependence on U.S. agricultural products, rather than the opposite. This situation is likely to be the case for the developing nations; where the increasing energy imports prices place serious constraints on their ability to expand agricultural investment. and production. The World Food council has projected that these countries will increasingly rely on grain and agricultural imports from the U.S. and other major producers. In the past, the U.S., under the PL 480 program, has sent over $\$ 5$ billion in agricultural commodities to developing countries in exchange for local currencies which are used to finance local development projects.

In the future, the U.S. will continue to emphasize its role as a major exporter of agricultural products in order to alleviate its own international balance of payments deficit. Indeed, in $1976 \mathrm{U} . \mathrm{S}$. agricultural exports neared $\$ 23$ billion or 76 percent of our total oil import bill. Imports of foreign agricultural products will be minor except for those items that climate conditions do not permit to be grown here. Commodities from sub-tropical countries, such as coffee, tea, and cocoa will continue to be the dominant products imported. The developing countries will moreover continue to push for greater access to markets in the U.S. and other industrial countries for their agricultural produce.

ii) The Department of Energy is embarking on a program of international energy development with less developed countries that is examining the energy needs of selected developing countries, in cooperation with the Department of state, the Agency for International Development, and other federal agencies. The energy requirements of the rural sector of these countries and of their agricultural production, distribution, and marketing systems are an important element of these assessments. Presently, AID with DOE laboratory support working on a comparative study of the role of energy in the food systems of several developing countries. And, DOE is also providing technical support for several. AID supported projects that involve the demonstration small-scale technologies. A great deal more, however, needs to be done to determine the energy 
supplies necessary to increase agricultural productivity in developing countries and to develop, transfer, and apply energy technologies, especially those using renewable resources, that are suitable to rural conditions of these countries. The DOE is actively considering possibilities as part of preparations for the United Nations Conference on Science and Technology for Development and the U.S. Domestic Policy Review on Solar Energy. 


\section{Question 35}

The great need of consumers is political direction from Executive department spokesmen to tell us, to suggest, to encourage us to adopt and indeed find new ways to conserve energy in the production, processing, and use of food--an area of energy within the control of every individual and business to some extent. Can the DOE help us here?

\section{Answer}

The Department of Energy has two programs which are relevant to this area. First, the Energy Extension Service program, which was begun in 1977 in 10 states on a two-year pilot basis. This program is oriented towards encouraging individuals and small establishments to adopt measures to reduce energy consumption and convert to renewable energy sources, by providing personalized assistance and information regarding energy-efficient techniques. The Extension Service will also provide feedback to DOE regarding energy research needs and requirements of small energy consumers.

Secondly, the DOE Office of Public Affairs has an extensive Speakers-Bureau specifically designed to meet consumer requests for public speakers. Hundreds of DOE representatives are sent throughout the country each year to meet with. school groups, conferences, annual conventions, etc. These spokesmen represent various, DOE regional and national offices. In order for the spokesmen to be most effective and knowledgable, the speakers Bureau conducts monthly training programs and follow-up refresher courses in speaking. The Bureau then selects representatives suited for each request. Groups that are interested in DOE speakers meeting with them should contact: DOE Speakers Bureau, Room 3118, 12th and Pennsylvania Ave., N.W., Washington, D.C. 20461. 
Question 36

The new tecinnologies being funded by the DOE will reduce energy costs and the costs of food, and thus, will determine the U.S. diet of the future. Will the DOE consider the nutritional value of the food when promoting its more efficient production?

\section{Answer}

The DOE is supporting the development of a dynamic simulation of the U.S. food system called AGRIMOD. AGRIMOD will assess the long term impacts of national policies on food supply and energy consumption. One of the submodels of the simulation will be a consumption analysis sector which will analyze food consumption in terms of calories and protein per capita. This information will be particularly helpful in inferring some socio-economic impacts of alternative policies. 


\section{Question 37}

Still the question remains, even though the weatherization program exists for low income, it is simply not enough. If in D.C. alone only 40 homes have been weatherized, how long will this process take, and is there enough funding available for this? How, until then, will people be able to afford food?

\section{Answer}

Implementation of the Department of Energy (DOE) Weatherization Assistance Program was initiated in the last quarter of calendar year 1977. During that quarter $\$ 27$ million in grants were awarded to the States and 24 Native American tribal organizations. Although many local projects did not receive funding until the spring of 1978, over 11,000 homes had been weatherized by March $30,1978$.

The DOE Regional offices are currently processing applications for FY 78 grants totaling $\$ 64,066,000$ out of a total appropriation of $\$ 65$ million. It is anticipated that the majority of grants will be awarded by June 30, 1978 .

DOE has requested a FY 79 appropriation for weatherization of $\$ 198,750,000$. Assuming a full appropriation, over 750,000 homes will have been weatherized by the end of the FY 79 program year. 
Question 38

Please answer question \#10, particularly with reference to DOE's and USDA's input in investigating alternatives to petroleum based pesticides. What is the percentage of nonchemical pesticide control methods at USDA and DOE?

\section{Answer}

The Department of Energy has no jurisdiction in the area of non-petroleum based pesticides development. Instead, Congress has mandated the Environmental Protection Agency with this authority. Under the Federal Insecticide, Fungicide, and Rodenticide Act, and the new Toxic Substances Act of 1976, the' EPA has been charged with reducing the serious health and environmental risks created by hazardous chemical substances.

Under a plan called IPM (Integrated Pest Management), the Agency has emphasized the use of natural control factors and has de-emphasized the role of chemical pesticides. Particular success has been achieved in the treatment of alfalfa plants in Utah. In addition, the IPM program has demonstrated the reduced use of pesticides through different application techniques, and has demonstrated alternative pesticide use on cotton fields in Texas and Arkansas. Further R\&D efforts are underway by the Agency. For the most part, though, IPM has achieved commercial use only in areas where high levels of insecticide resistance have developed in insect pests, thereby forcing farmers to seek alternative solutions to conventional pesticides.

Since 1956, USDA has been working for the development of alternative pesticides. While the Department has registered four pathogins with EPA, these alternatives have not gained wide acceptance. Indeed, the petroleum based pesticides have a number of advantages in that they serve a broad spectrum of materials, are less expensive to use, cause minimum damages to crops, and are simple and easy to use: On the other hand, the alternatives developed to date are more narrow in their field of use, require a more sophisticated control system, and have monitoring and data costs which are prohibitive for some pests.

Although, USDA is working to integrate the methodology of pest elimination, few breakthroughs can be expected that would radically change pesticides usage. Currently, $80 \%$ of the billion pounds of pesticides used in the U.S. are chemically based. This figure does not include pesticides whose production or extraction processes require petroleum based solvents, nor does it account for the use of petrochemicals or "inert" ingredients in non-petroleum pesticides. Thus, it seems that for a good number of years, petroleum based pesticides will continue to dominate the market at at least the proportion that currently exists. 